\title{
Three-Dimensional Thermo-Elastic-Plastic Finite Element Method Modeling for Predicting Weld-Induced Residual Stresses and Distortions in Steel Stiffened-Plate Structures
}

\author{
Myung Su Yi1,2, Chung Min Hyun², Jeom Kee Paik ${ }^{1,3,4^{*}}$ \\ ${ }^{1}$ Department of Naval Architecture and Ocean Engineering, Pusan National University, Busan, Korea \\ ${ }^{2}$ Central Research Institute, Samsung Heavy Industries Co., Ltd., Geoje, Korea \\ ${ }^{3}$ The Korea Ship and Offshore Research Institute (The Lloyd's Register Foundation Research Centre of Excellence), Pusan National \\ University, Busan, Korea \\ ${ }^{4}$ Department of Mechanical Engineering, University College London, London, UK \\ Email: ${ }^{\star}$ jeompaik@pusan.ac.kr
}

How to cite this paper: Yi, M.S., Hyun, C.M. and Paik, J.K. (2018) Three-Dimensional Thermo-Elastic-Plastic Finite Element Method Modeling for Predicting Weld-Induced Residual Stresses and Distortions in Steel Stiffened-Plate Structures. World Journal ot Engineering and Technology, 6, 176-200. https://doi.org/10.4236/wjet.2018.61010

Received: December 18, 2017

Accepted: February 24, 2018

Published: February 27, 2018

Copyright $\odot 2018$ by authors and Scientific Research Publishing Inc. This work is licensed under the Creative Commons Attribution International License (CC BY 4.0).

http://creativecommons.org/licenses/by/4.0/

\begin{abstract}
The objective of the present paper is to develop nonlinear finite element method models for predicting the weld-induced initial deflection and residual stress of plating in steel stiffened-plate structures. For this purpose, three-dimensional thermo-elastic-plastic finite element method computations are performed with varying plate thickness and weld bead length (leg length) in welded plate panels, the latter being associated with weld heat input. The finite element models are verified by a comparison with experimental database which was obtained by the authors in separate studies with full scale measurements. It is concluded that the nonlinear finite element method models developed in the present paper are very accurate in terms of predicting the weld-induced initial imperfections of steel stiffened plate structures. Details of the numerical computations together with test database are documented.
\end{abstract}

\section{Keywords}

Steel Stiffened-Plate Structures, Weld-Induced Initial Distortion, Weld-Induced Residual Stress, Nonlinear Finite Element Method, Three-Dimensional Thermo-Elastic-Plastic Finite Element Analysis, Full Scale Measurements

\section{Introduction}

Ships and offshore structures are fabricated by welding and thus weld-induced 
initial imperfections in the form of initial distortions and residual stresses are unavoidable. It is required to predict the weld-induced initial imperfections in magnitude and pattern in association with structural design and construction.

A large number of studies are found in the literature. In recent years, these studies are associated with weld-induced initial distortions [1] [2] [3] [4] [5] and welding-induced residual stresses [6] [7] [8] [9] [10]. Figure 1 shows typical modes of weld-induced initial distortions in plated structures [11] [12].

Simplified methods to predict weld-induced initial distortions are available in the literature [13]-[18]. However, weld-induced initial imperfections are affected by various parameters such as weld joint details, plate thickness, thickness transition (when the joint consists of plates with different thicknesses), stiffener spacing, numbers of attachments, corrugated constructions, mechanical restraint conditions, assembly sequences and overall construction planning [19]. In this regard, more refined method is still required to accurately predict them.

Nonlinear finite element method is a powerful tool to predict the weld-induced initial imperfections as it can deal with the distribution of heat transfer and general deformation due to welding. Ueda and Murakawa [20] undertook a pioneering work using two-dimensional finite element method to predict weld-induced residual stresses. Lindgrean and Karlsson [21] are the first to use three-dimensional finite element method for predicting weld-induced residual stresses. Chen and Guedes Soares [22] also used the three-dimensional finite element method to predict the weld-induced residual stresses with a validation by a comparison with test database on small scale models.

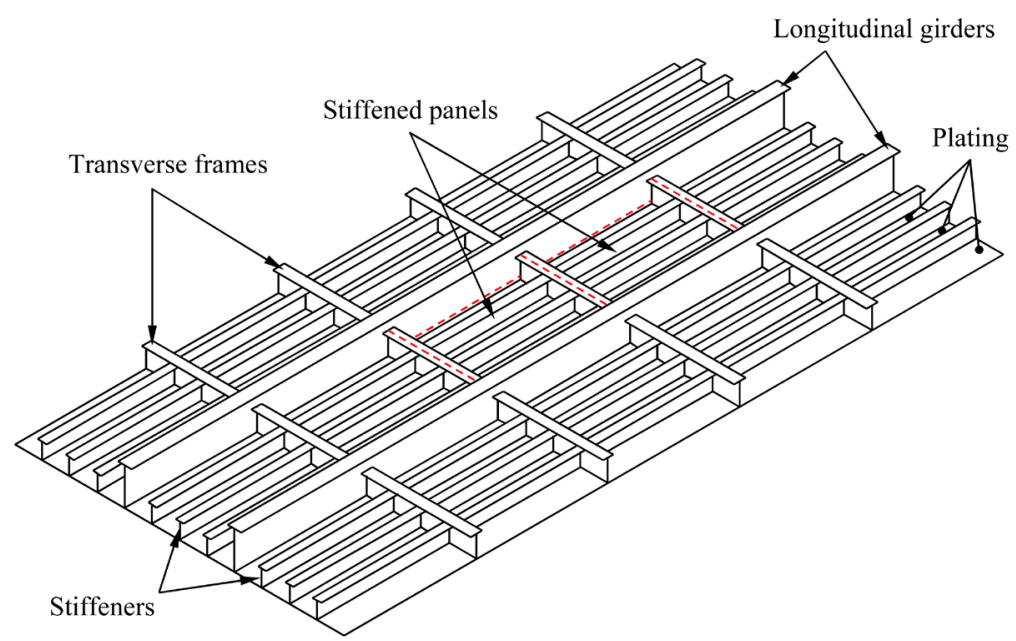

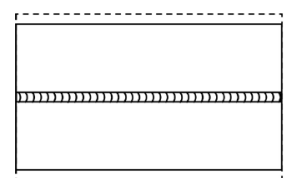

Transverse Shrinkage

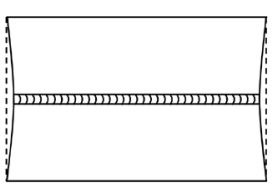

Longitudinal Shrinkage

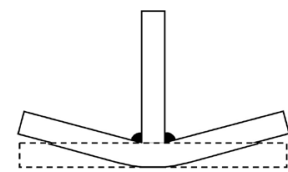

Angular Change

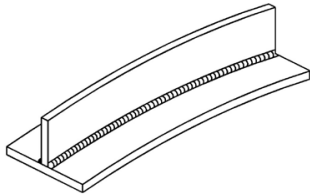

Longitudinal Bending Distortion

Figure 1. Typical modes of weld-induced initial distortions in plated structures [11] [12]. 
Studies on predicting the weld-induced initial distortions using finite element method are also found in the literature [23]-[28]. It was realized from the studies that the computing times are very expensive, and thus simplified methods using inherent strain have been suggested [27] [29] [30]. Michaleris and DeBiccari [31] developed a useful method to predict weld-induced distortions of large and complex structures, where two-dimensional thermal analysis was performed while three-dimensional structural analysis was undertaken. Regardless of the useful contributions in the literature, more efforts are still required for predicting the weld-induced initial imperfections of ships and offshore structures in association with welding and repair methods as well as robust design [32].

And, studies on repair welding using finite element method and experiment are also found in the literature [33] [34] [35].

In this paper, a three-dimensional thermo-elastic-plastic finite element method model is developed to predict the weld-induced distortions and residual stresses of thin-walled structures while achieving the goals in resulting accuracy and computational cost. The validity of the method is confirmed by a comparison with test database separately obtained from the full scale measurements by the authors.

\section{Finite Element Modeling for Predicting the Weld-Induced Residual Stresses}

In this section, the finite element model is presented to predict the weld-induced residual stresses. The three-dimensional thermo-elastic-plastic finite element analysis method is applied.

Welding residual stress analysis is a complex problem requiring a lot of knowledge such as solid mechanics, heat transfer, materials science and so on. An important feature of this problem is the nonlinearity of the material. That is, material properties such as thermal conductivity, heat capacity, elastic modulus, yield stress, and Poisson's ratio vary sensitively with temperature. Particularly in the case of welding, there is sudden change of the temperature from the atmospheric temperature to the melting temperature of the metal. In addition, during the thermal transition period, the material experiences state changes from the solidus to the liquidus, or vice versa. These state changes produce changes in material properties and specific volume. This is generally explained by the coefficient of thermal expansion. For this reason, it is very difficult to obtain an analytical solution to the temperature and stress field. However, recent advances in finite element analysis using computer have led to many improvements in the residual stress analysis of welding. In general, the finite element method provides very detailed information on transition temperature, displacement, strain and stress. This FE method provides an accurate solution to the welding problem. This is possible because the temperature-dependent changes in the material properties of the material can be taken into account and properties such as the state of the weld and the phase change can be sufficiently modeled. As described 
above, the features of the welding problem requires consideration of many physical phenomena. Figure 2 shows the form of the connection between thermal, mechanical and metallurgical processes for the phenomena occurring during the welding process. This method is used to analyze the weld-induced residual stress.

The validation of the finite element model is made by a comparison with test database obtained by Paik and Yi [36]. The MSC/MARC computer program [37] is used for computations in the present study.

\subsection{Modeling of Heat Source}

As heat source moves associated with welding, the heat input can change accordingly. Rosenthal [38] suggested a model to simulate the moving heat source although the distribution of heat input was not considered due to the change of heat source. Goldak et al. [39] suggested a model to consider thermal distribution through moving heat source using Gaussian surface or double-ellipsoidal distributions. For welding with low depth of penetration, the Gaussian surface distribution model is well more suitable to apply. However, as the weld penetration becomes deep like in shipbuilding industry practice, heat transfer is of significance in the thickness direction. In this case, the double-ellipsoidal distribution model is more suitable.

Figure 3 presents the configuration of the heat source distribution with a double ellipsoidal shape. The heat flux for the first half-ellipsoidal internal area located at the front of the welding arc can then be defined as follows:

$$
q_{f}(x, y, z)=\frac{6 \sqrt{3} f_{f} Q}{a b c_{f} \pi \sqrt{\pi}} \exp \left(\frac{-3 x^{2}}{a^{2}}\right) \exp \left(\frac{-3 y^{2}}{b^{2}}\right) \exp \left(\frac{-3 z^{2}}{c_{f}^{2}}\right)
$$

at $z \geq 0$

where $q_{f}(x, y, z)$ is the heat flux for the first half-ellipsoidal internal area located at the front of the welding arc, $f_{f}$ is the heat input proportion in the front part, $Q$ is the heat flux of arc which is taken as $Q=\eta I U, a, b$ and $c_{f}$ are geometric parameters, and $\eta$ is the arc efficiency, $I$ is the current and $U$ is

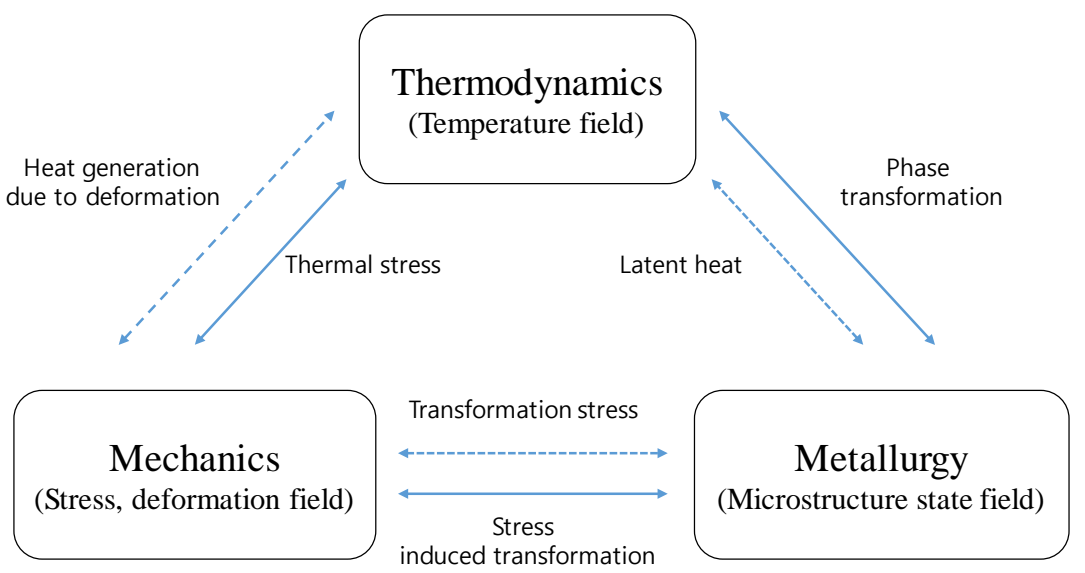

Figure 2. Schematic diagram coupling between temperature, microstructure and stress. 


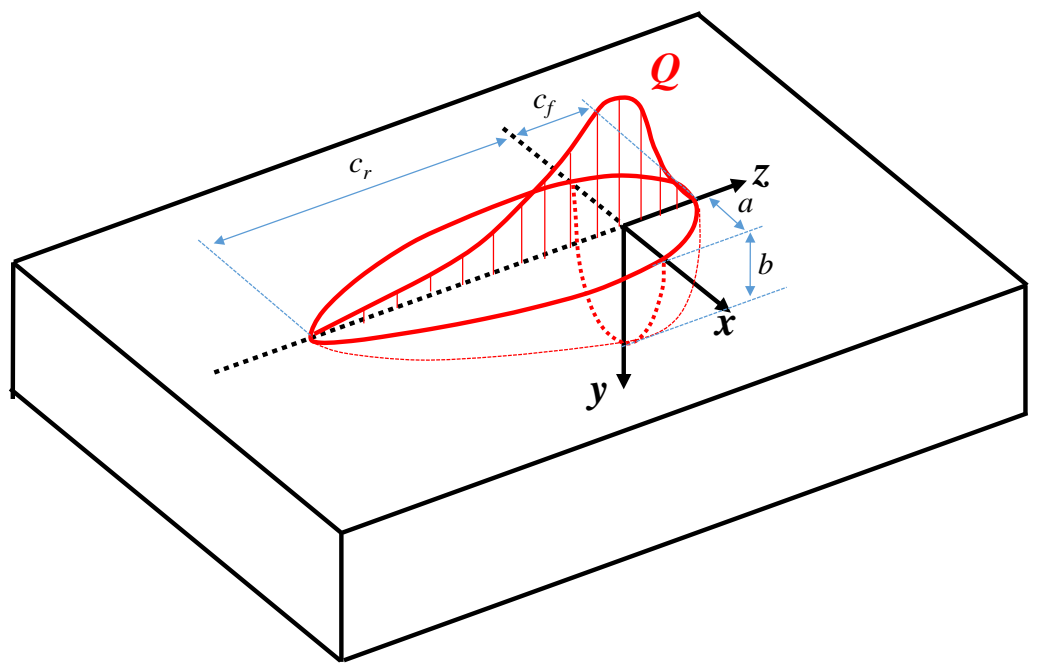

Figure 3. Definition of geometric parameters for the heat source distribution with a double-ellipsoidal shape [39].

the voltage. $x, y$ and $z$ are the coordinate where the origin is located on the weld surface below the heat source as shown in Figure 2.

The arc efficiency $\eta$ is defined as the ratio of the heat transferred from the arc to the base material and the total heat generated by the arc, which is a constant simply indicative of the complex heat loss between the substrates in the arc. Since the arc efficiency is influenced by various factors such as welding conditions, melting depth and protective gas, it is very challenging to predict it theoretically and it is usually determined experimentally. This is because the arc efficiencies given in the literature are somewhat different from each other. For flux cored arc welding considered in the present method, $\eta=0.75$ is usually taken.

The heat flux at any point $(x, y, z)$ in the second semi-ellipsoid covering the rear part of the arc can be defined as follows:

$$
q_{r}(x, y, z)=\frac{6 \sqrt{3} f_{r} Q}{a b c_{r} \pi \sqrt{\pi}} \exp \left(\frac{-3 x^{2}}{a^{2}}\right) \exp \left(\frac{-3 y^{2}}{b^{2}}\right) \exp \left(\frac{-3 z^{2}}{c_{r}^{2}}\right)
$$

at $z<0$

where $q_{r}(x, y, z)$ is the heat flux at any point $(x, y, z)$ in the second semi-ellipsoid covering the rear part of the arc, $c_{r}$ is the geometric parameter, and $f_{r}$ is the heat input proportion in the rear part. It is realized that $f_{f}+f_{r}=2$ is approximately taken as far as the following conditions are satisfied:

$$
f_{f}=\frac{2}{\left(1+c_{r} / c_{f}\right)}, \quad f_{r}=\frac{2}{\left(1+c_{f} / c_{r}\right)}
$$

\subsection{Geometric Properties}

Figure 4 shows a steel stiffened-plate structure which is extracted from living quarter structures of a very large crude oil carrier (VLCC) class floating, production, storage and offloading (FPSO) unit which is used for the production of oil in deep water. Typically, the longitudinal stiffener spacing (plate breadth) is in 
the range of $800-1000 \mathrm{~mm}$, the transverse stiffener spacing (plate length) is in the range of $1800-3600 \mathrm{~mm}$, and the plate thickness is in the range of $6-13 \mathrm{~mm}$.

Paik and Yi [36] measured the weld-induced residual stresses of the structure shown in Figure 4 where angle type longitudinal stiffener and $\mathrm{T}$ type transverse stiffener as shown in Figure 5 are used. Table 1 indicates the overall dimensions of the test structures. The weld-induced residual stresses for a total of four structures were measured with varying the plate thickness. It was noted that $1 / 2$ $+1+1 / 2$ bay structure model could minimize the interacting effect of adjacent plate panels. While details of the measurements are referred to in Paik and Yi [36], the finite element model presented in this paper is validated by a comparison with the measurements. A quarter of the structure is taken as the extent of the present finite element analysis for the geometric symmetry as shown in Figure 4. Table 1 indicates the geometric properties of the structures where the

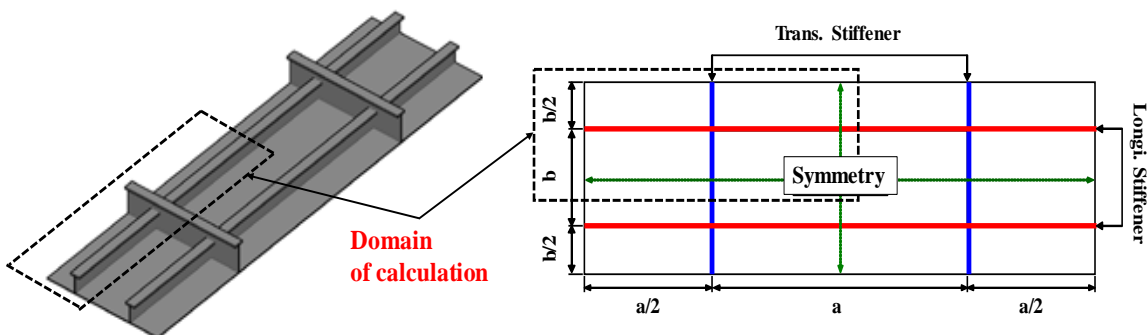

Figure 4. A steel stiffened-plate structure to measure the weld-induced residual stresses [36].

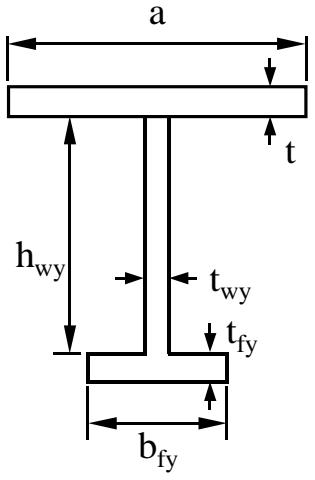

(a)

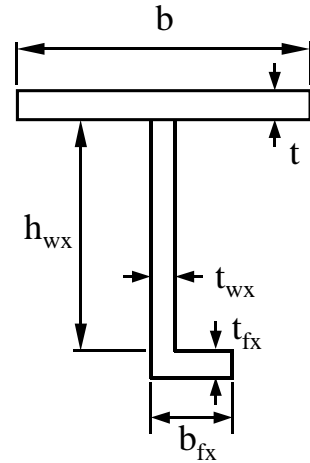

(b)

Figure 5. Types of stiffeners used in the test structures [36]. (a) Transverse stiffener; (b) Longitudinal stiffener.

Table 1. Dimensions of the test structures considered [33].

\begin{tabular}{cccccccccc}
\hline Type & $\begin{array}{c}a \\
{[\mathrm{~mm}]}\end{array}$ & $\begin{array}{c}b \\
{[\mathrm{~mm}]}\end{array}$ & $\begin{array}{c}t_{p} \\
{[\mathrm{~mm}]}\end{array}$ & $\begin{array}{c}L_{W} \\
{[\mathrm{~mm}]}\end{array}$ & $\begin{array}{c}\text { Stiffener } \\
\text { Type }\end{array}$ & $\begin{array}{c}h_{w} \\
{[\mathrm{~mm}]}\end{array}$ & $\begin{array}{c}t_{w} \\
{[\mathrm{~mm}]}\end{array}$ & $\begin{array}{c}b_{f} \\
{[\mathrm{~mm}]}\end{array}$ & $\begin{array}{c}t_{f} \\
{[\mathrm{~mm}]}\end{array}$ \\
\hline & & & 6 & & Longi. & 125 & 7 & 75 & 7 \\
Deck & 3200 & 800 & 8 & 6.5 & & & & & \\
& & & 10 & & Trans. & 350 & 12 & 100 & 17 \\
\hline
\end{tabular}

Note: $L_{w}$ indicates the weld bead length (leg length of welding). 
plate thickness is varied as $6,8,10$ and $12 \mathrm{~mm}$.

\subsection{Material Properties}

Table 2 indicates the mechanical properties of material at room temperature. During welding, the material properties greatly change with elevated temperatures as described in Figure 6 [40]. It is noted that the minimum requirement of the yield strength specified by classification societies is $235 \mathrm{MPa}$ for mild steel which is used for construction of the living quarter structures, but the actual yield strength of $309 \mathrm{MPa}$ is used for the finite element analysis in the present study.

Table 2. Mechanical properties of steel at room temperature used for the living quarter structures.

\begin{tabular}{cccccc}
\hline Kind of material & $E[\mathrm{GPa}]$ & $\sigma_{Y}[\mathrm{MPa}]$ & $\sigma_{u}[\mathrm{MPa}]$ & $v[-]$ & Elongation $[\mathrm{mm} / \mathrm{mm}]$ \\
\hline Mild A & 203 & 309 & 458 & 0.3 & 0.23 \\
\hline
\end{tabular}

Note: $E$ is the elastic modulus, $\sigma_{Y}$ is the yield strength, $\sigma_{u}$ is the ultimate tensile strength, and $v$ is the Poisson's ratio.
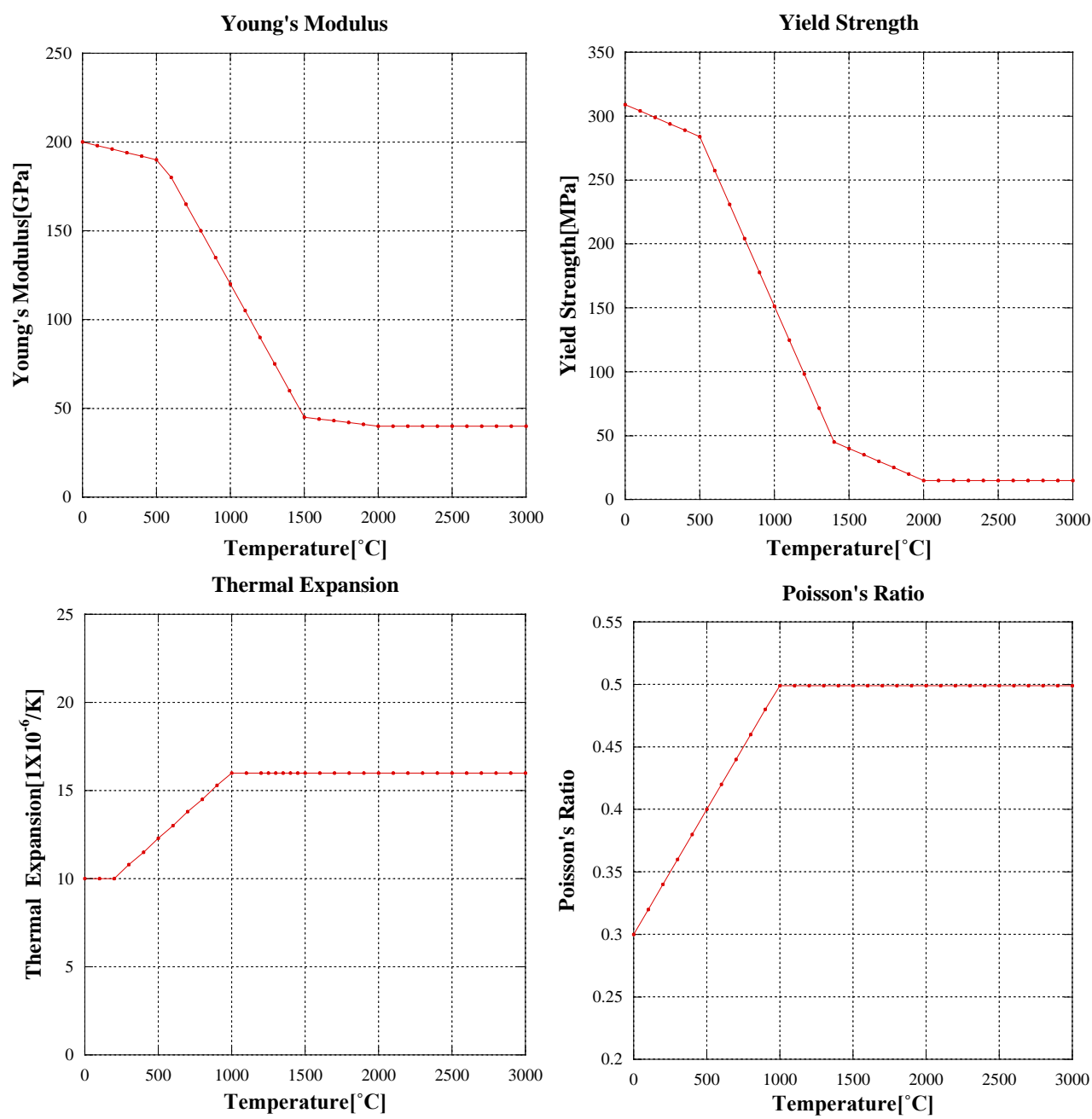

(a) 

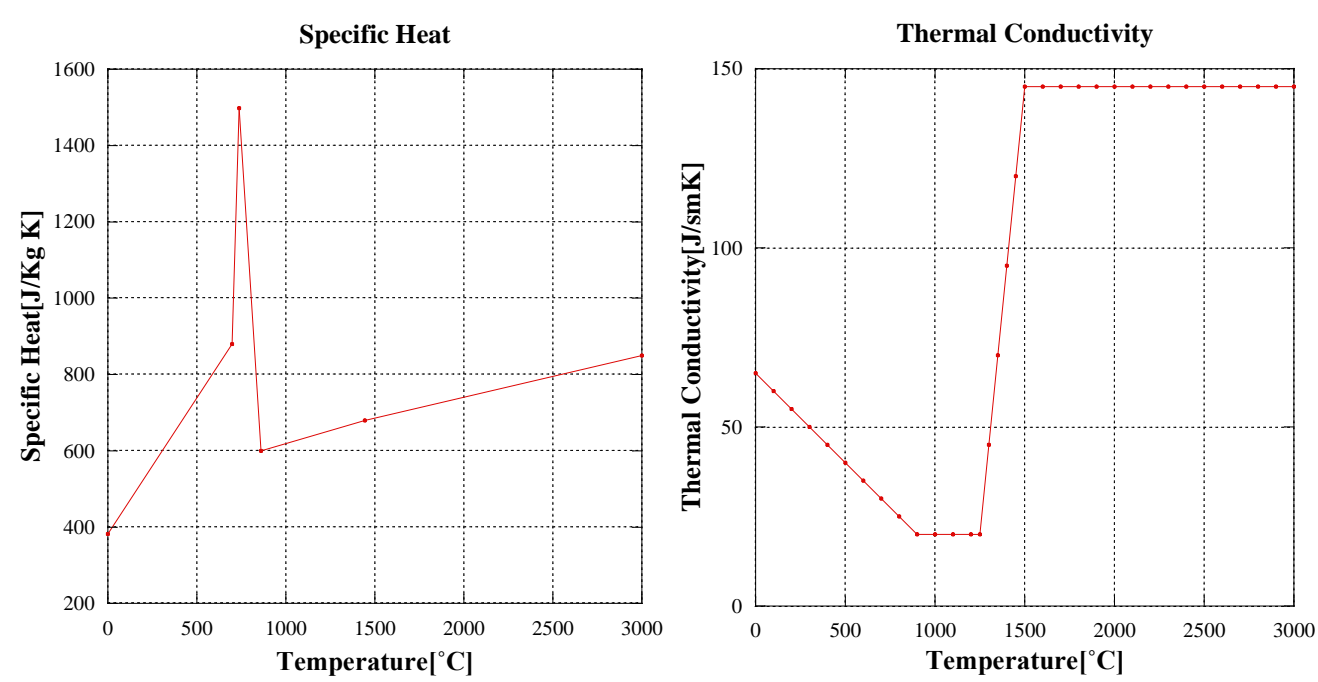

(b)

Figure 6. Mechanical and thermal properties [40]. (a) Mechanical properties; (b) Thermal properties.

\subsection{Thermal Loading Load and Boundary Conditions}

As mentioned earlier, a quarter model of the target structure is applied as the extent of the finite element analysis as shown in Figure 4 in association with the symmetric condition. Figure 7 shows the sample model of the thermo-elastic-plastic finite element analysis together with loading and boundary conditions where the welding sequence is divided into 8 zones in the same order as the actual welding sequence. The structure is modelled using eight-node $3 \mathrm{D}$ brick thermal-mechanical finite elements or Solid 7 (full integration type) elements which treat plasticity, hyper-elasticity, stress stiffening, creep, large deflection, and large strain capabilities [37].

Welding heat input is applied using the dual heat source model where thermal loading and boundary conditions with convection and radiation are allocated. With convective conditions, the related constants depending on elevated temperature are defined from the database obtained from experiments and computational fluid dynamics simulations [41]. Figure 8 shows the variation of the temperature-dependent convection coefficient values [41].

Table 3 indicates the heat input defined from welding parameters associated with weld bead length applied in the present study. Table 4 gives the values of double ellipsoidal moving source model [22].

\subsection{Computed Results and Discussion}

Figure 9(a) shows the process of the moving heat source and resulting temperature distributions when welding is performed at the second weld zone. Figure 9(b) shows the equivalent von Mises stress distribution for the structure with a plate thickness of $6 \mathrm{~mm}$ after welding and cooling are completed.

Figure 10 shows the residual stress perpendicular to the weld line in relation to the section surface in the direction of each stiffener for a $6 \mathrm{~mm}$ thickness model. 


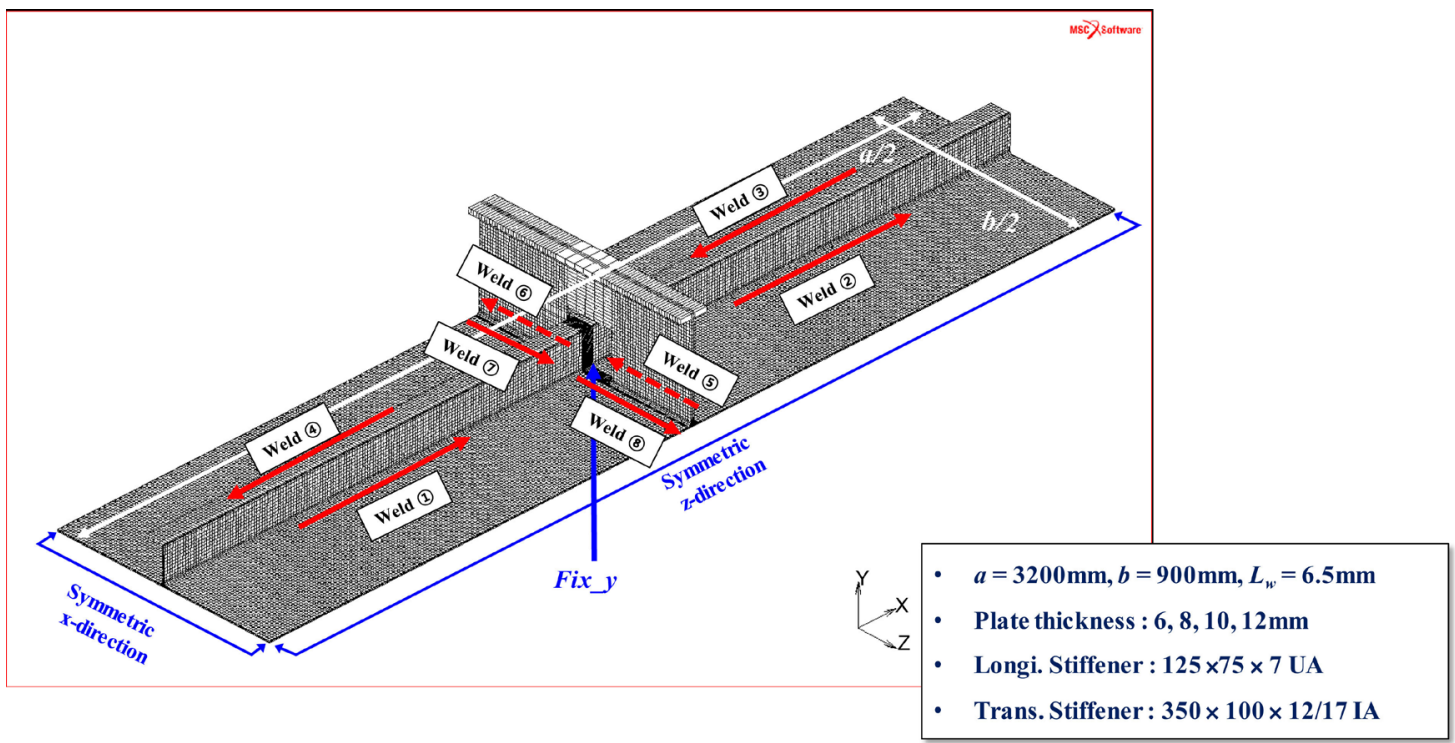

Figure 7. Thermal loading and boundary conditions for a quarter model of the structure.

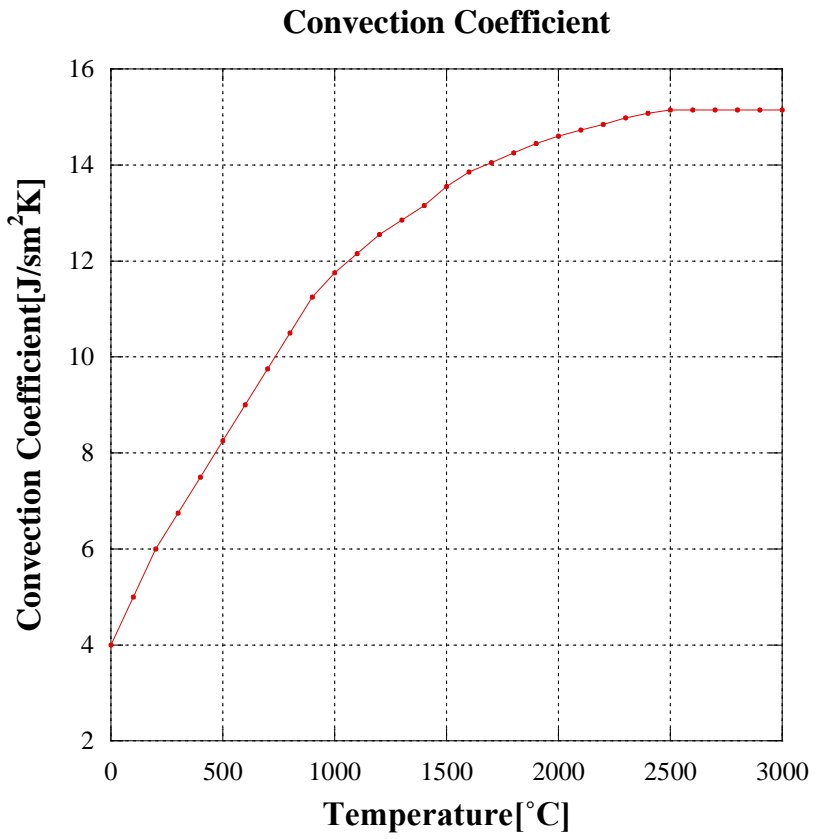

Figure 8. Variation of the temperature-dependent convection coefficient [41].

Table 3. Welding parameter for leg length.

\begin{tabular}{cccccc}
\hline $\begin{array}{c}\text { Leg length } \\
{[\mathrm{mm}]}\end{array}$ & $\begin{array}{c}\text { Current } \\
{[\mathrm{A}]}\end{array}$ & $\begin{array}{c}\text { Voltage } \\
{[\mathrm{V}]}\end{array}$ & $\begin{array}{c}\text { Speed } \\
{[\mathrm{CPM}]}\end{array}$ & $\begin{array}{c}\text { Speed } \\
{[\mathrm{mm} / \mathrm{s}]}\end{array}$ & $\begin{array}{c}\text { Heat input } \\
{[\mathrm{KJ} / \mathrm{mm}]}\end{array}$ \\
\hline 6.5 & 320 & 32 & 36 & 6.0 & 1.71 \\
\hline
\end{tabular}

Table 4. Values of the double ellipsoidal heat source model [22].

\begin{tabular}{cccccc}
\hline$a[\mathrm{~mm}]$ & $b[\mathrm{~mm}]$ & $c_{f}[\mathrm{~mm}]$ & $c_{f}[\mathrm{~mm}]$ & $f_{f}$ & $f_{r}$ \\
\hline 4 & 4 & 4 & 16 & 0.4 & 1.6 \\
\hline
\end{tabular}




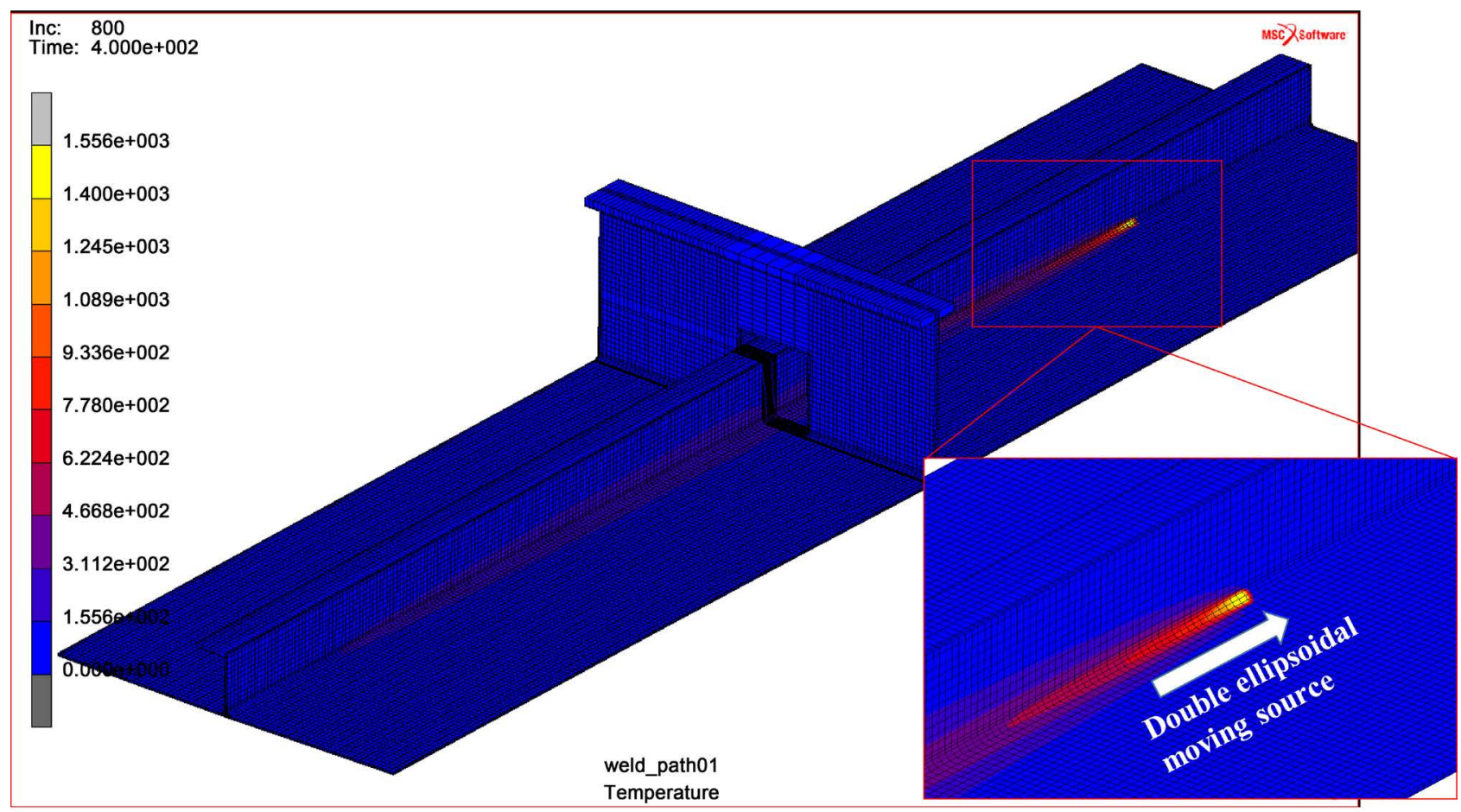

(a)

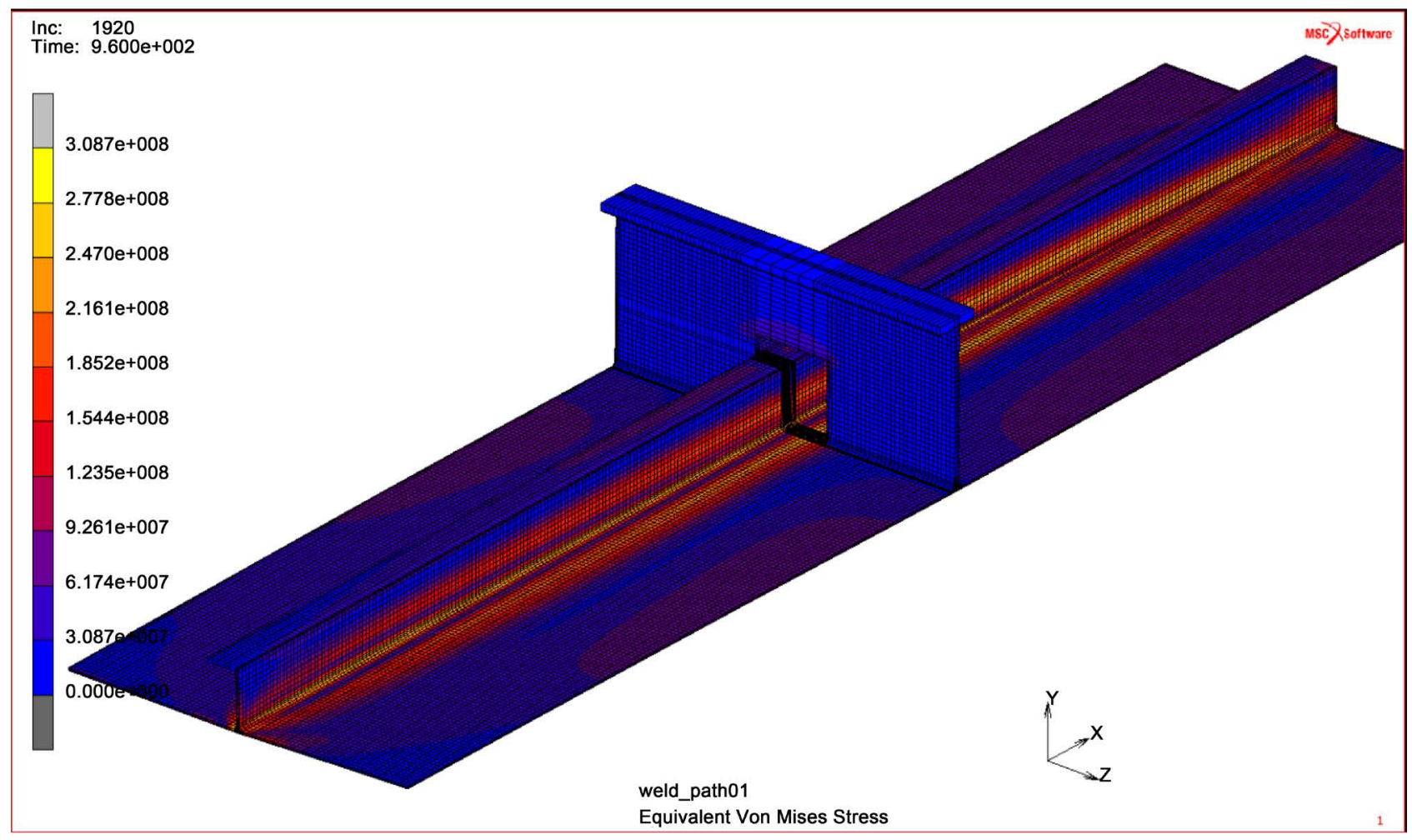

(b)

Figure 9. Computed results of welded-induced residual stress. (a) Schematic of moving heat source in the second weld zone with $t_{p}=6 \mathrm{~mm}$. (b) Distribution of equivalent von Mises stresses after $2^{\text {nd }}$ welding with $t_{p}=6 \mathrm{~mm}$. 


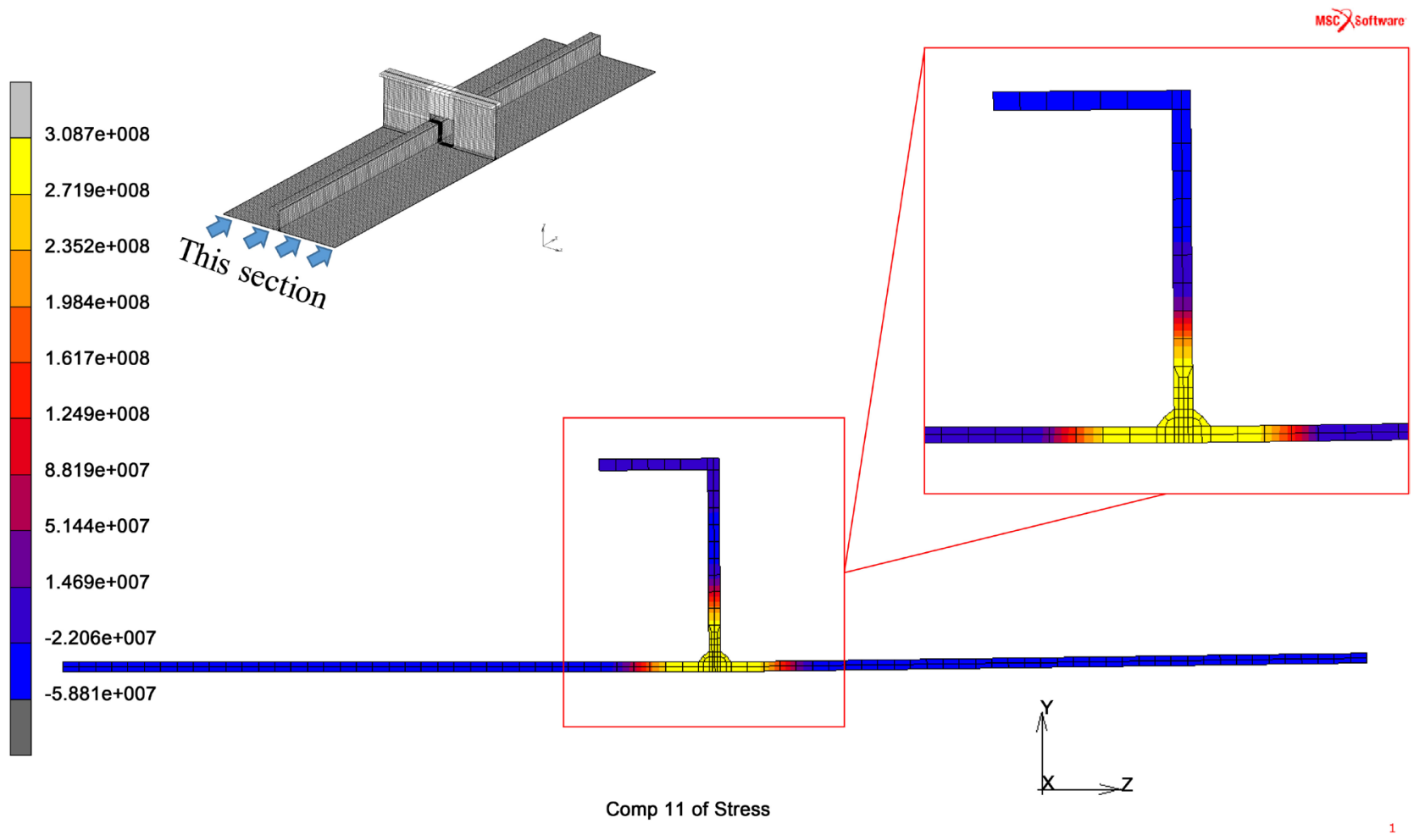

(a)

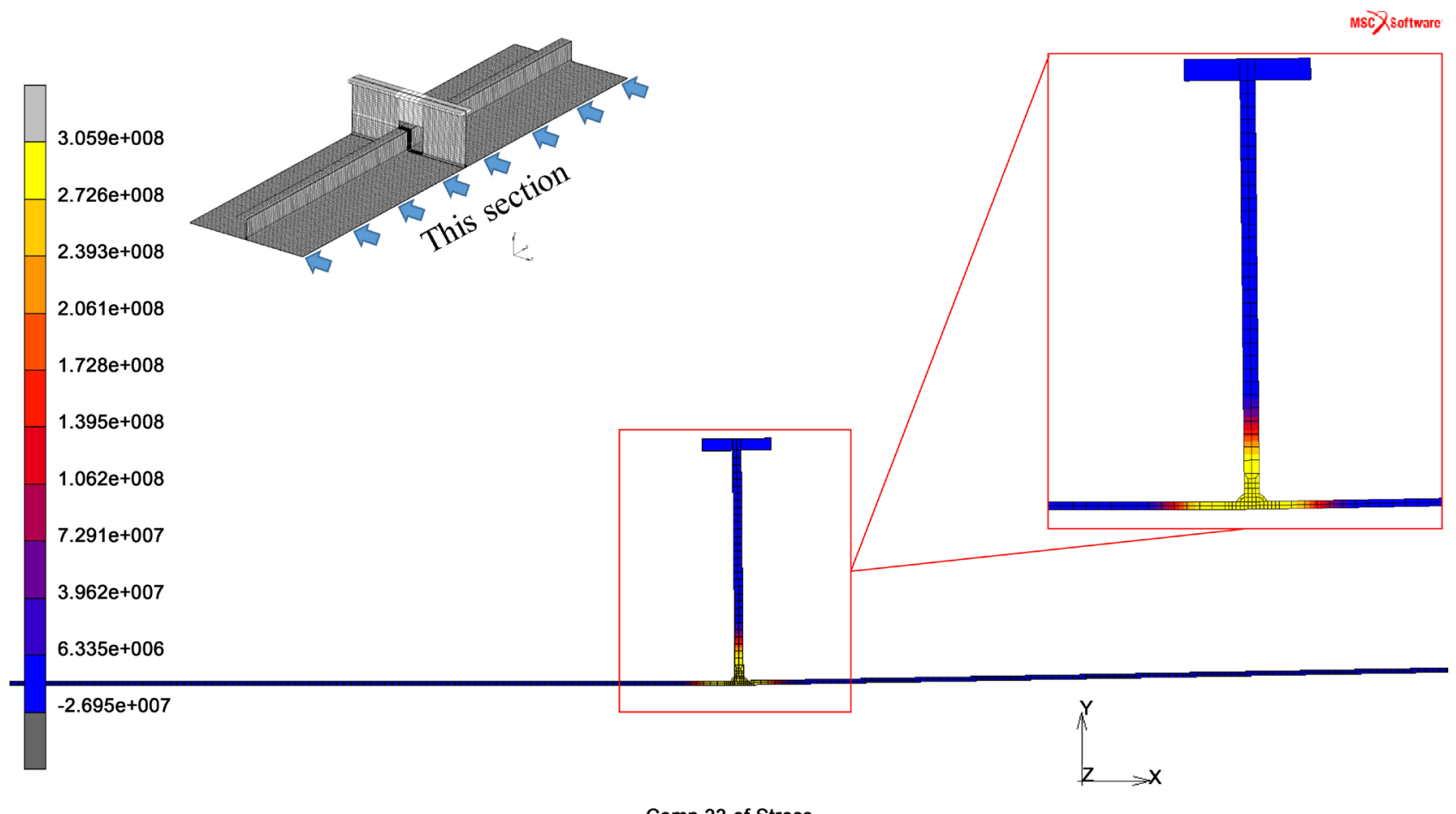

Comp 33 of Stress

(b)

Figure 10. Computed results of welding-induced residual stresses in transverse and longitudinal directions. (a) Distribution of residual stress in the transverse direction section with $t_{p}=6 \mathrm{~mm}$. (b) Distribution of residual stress in the longitudinal direction section with $t_{p}=6 \mathrm{~mm}$. 
The observed residual stress distribution is typically characterized by a high tensile stress near the weld bead and a distribution of compressive stress as it moves away from the weld.

\subsection{Comparison with Test Data}

Paik and Yi [36] performed the experiment to obtained test database of the welding-induced residual stresses in a full scale prototype structure. Figure 11 compares the experiments and the present computations. It is obvious that the welding-induced residual stresses are affected by plate thickness. With increase in the plate thickness, the compressive residual stresses decrease. It is also found that the magnitude of tensile residual stresses developed in the heat-affected zone reaches the material yield stress. The breadth of the heat-affected zone tends to decrease as the plate thickness increases for the same heat input. This may be due to the fact that the thermal load due to heat transfer is increased in the plate thickness direction and subsequently the magnitude of compressive residual stresses tends to decrease with increase in the plate thickness.

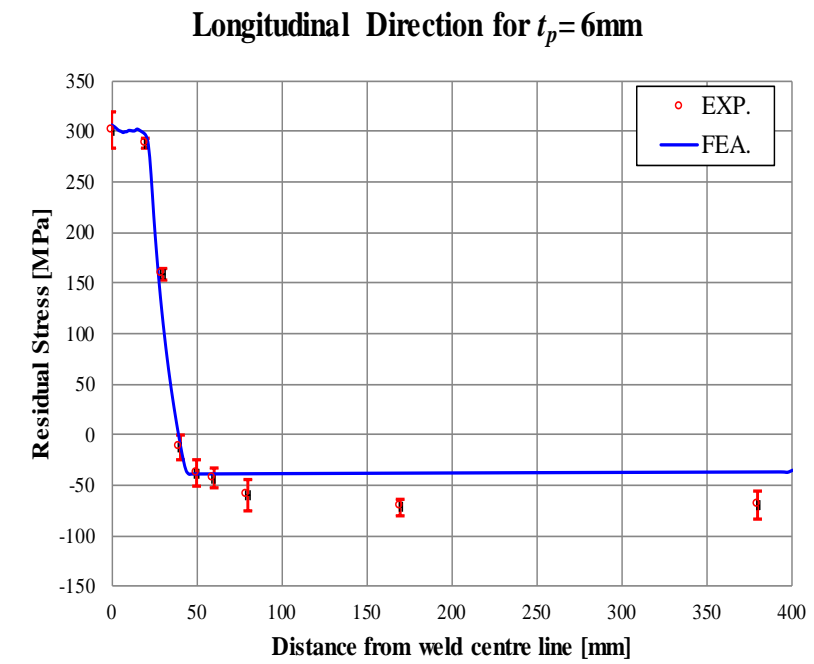

Longitudinal Direction for $t_{p}=10 \mathrm{~mm}$

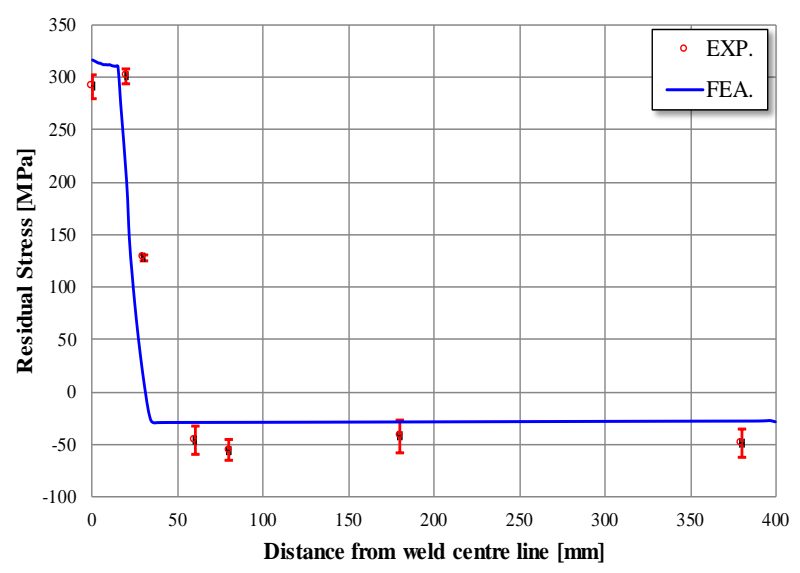

Longitudinal Direction for $t_{p}=8 \mathrm{~mm}$

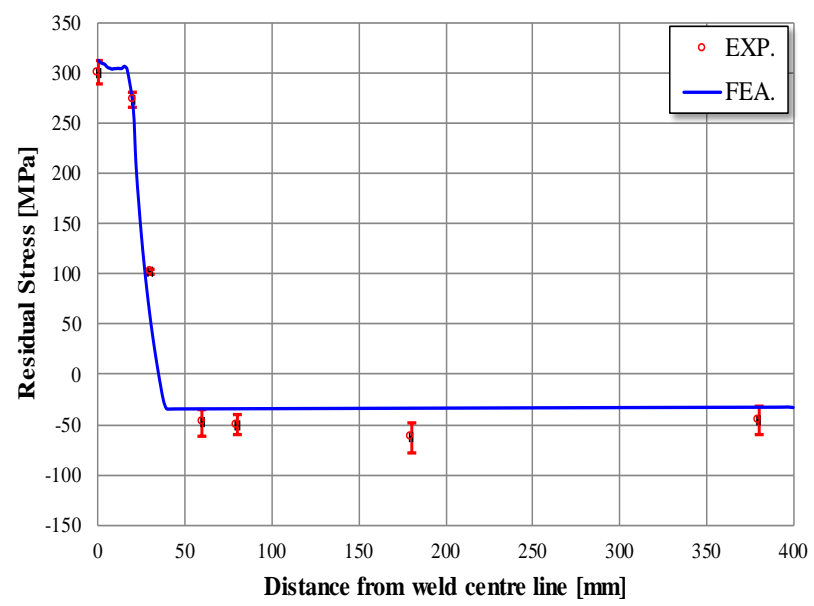

Longitudinal Direction for $t_{p}=12 \mathrm{~mm}$

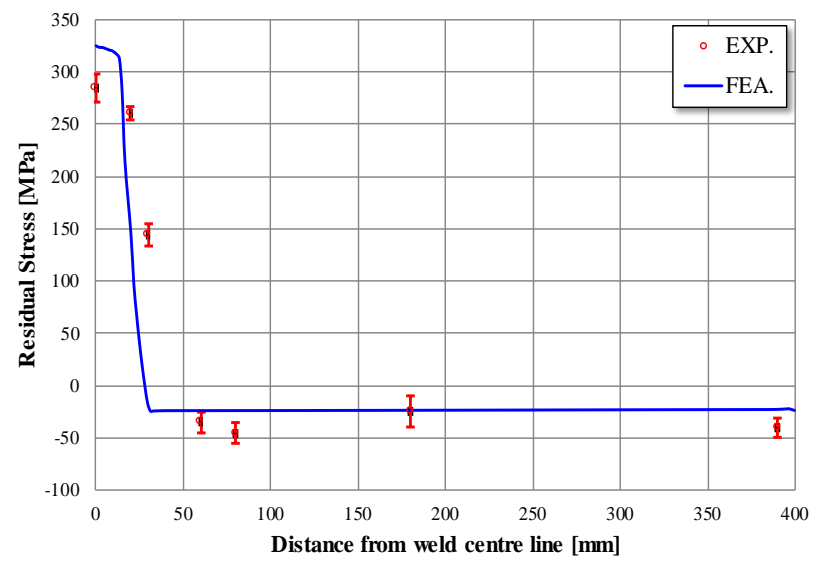

(a) 
Transverse Direction for $t_{p}=6 \mathrm{~mm}$

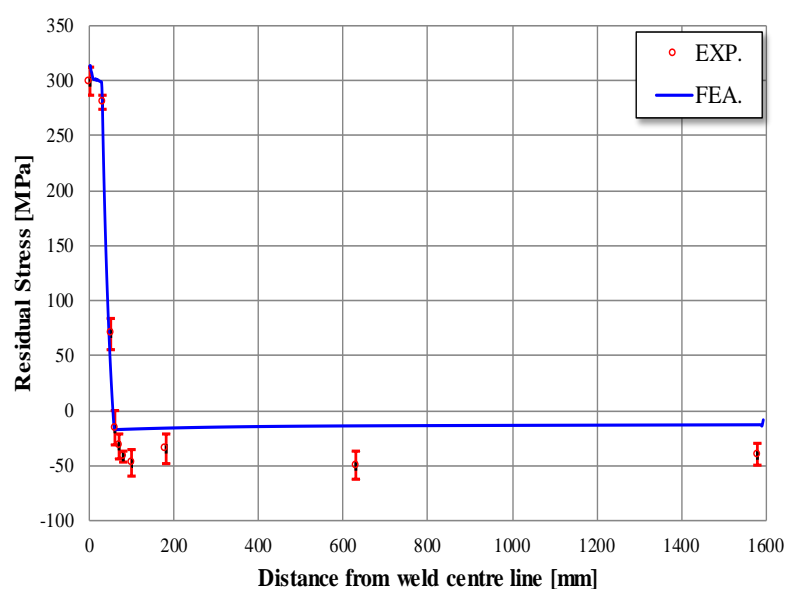

Transverse Direction for $t_{p}=10 \mathrm{~mm}$

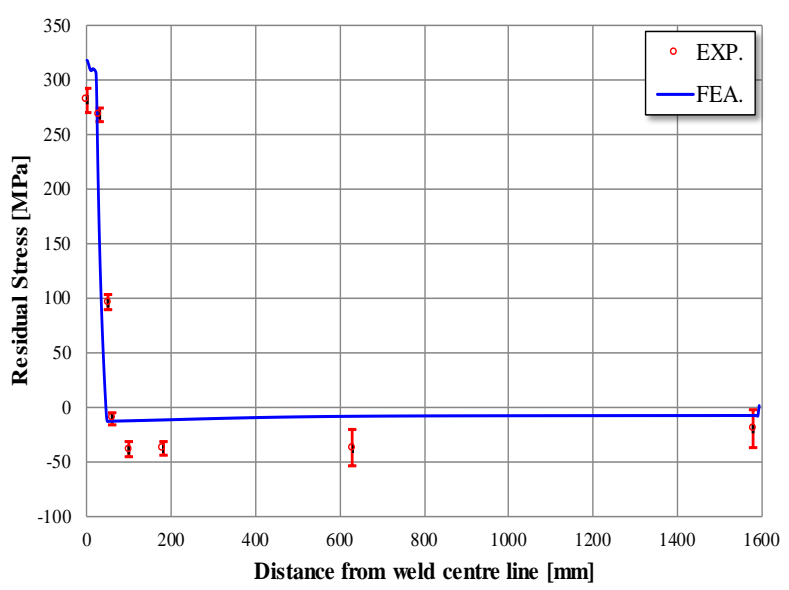

Transverse Direction for $t_{p}=8 \mathrm{~mm}$

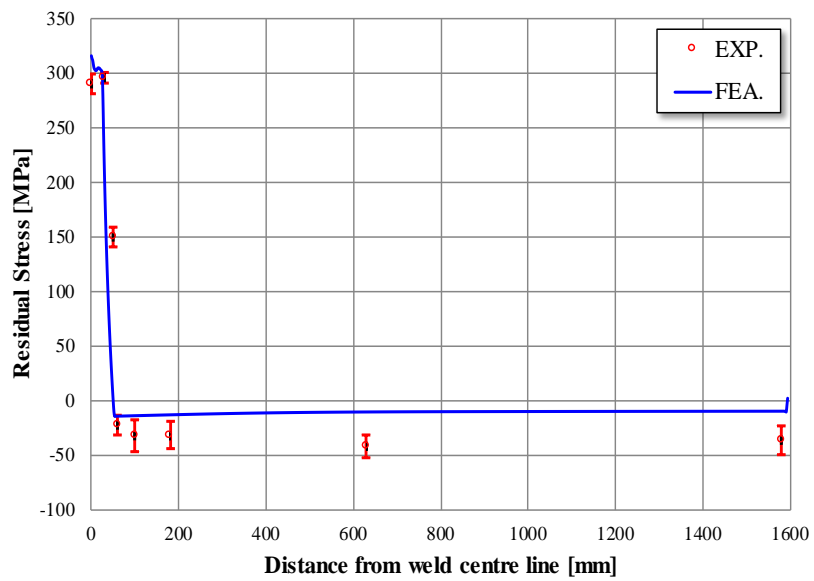

Transverse Direction for $t_{p}=12 \mathrm{~mm}$

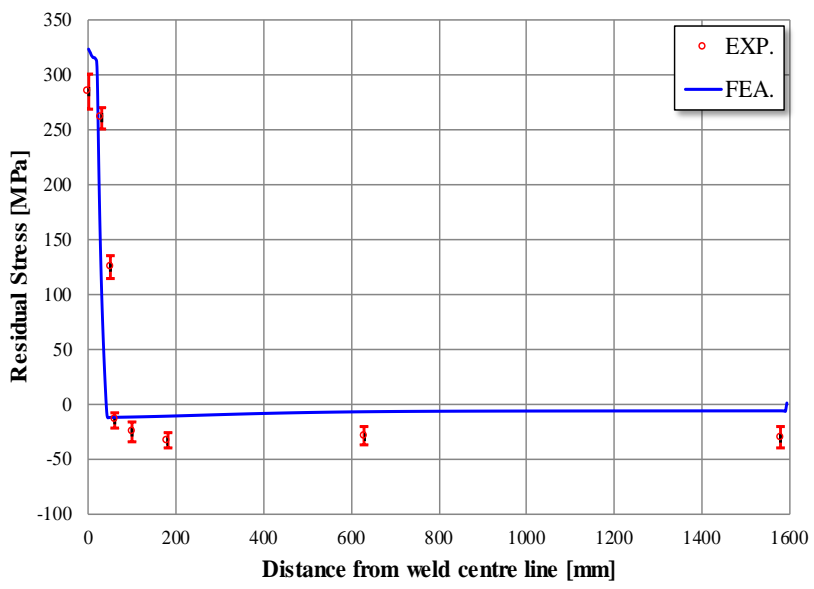

(b)

Figure 11. Comparison between the experiment and the computations. (a) Comparison of residual stresses in the longitudinal direction; (b) Comparison of residual stresses in the transverse direction.

It is concluded that the present finite element analysis model gives very good agreements with test database.

\section{Finite Element Modelling for Predicting the Weld-Induced Distortions}

In this section, the finite element model is presented to predict the weld-induced distortions. The thermal buckling analysis method is applied. The validation of the finite element model is made by a comparison with test database obtained from Paik and Yi [36]. The MSC/MARC computer program [37] is used for computations in the present study.

\subsection{Procedure of the Analysis}

Figure 12 presents the procedure for the nonlinear finite element analysis to predict the weld-induced distortions comprising 3 steps [42]. In step I, the welding 


\begin{tabular}{|c|c|}
\hline \multicolumn{2}{|c|}{ Step I Welding analysis for initial imperfection (SDB method) } \\
\hline $\begin{array}{l}\text { Pre- } \\
\text { processing }\end{array}$ & $\begin{array}{ll}\text { 1) Modeling } & \text { : Mesh generation based on CAD } \\
\text { 2) Material property input } & \text { : Thermal \& Mechanical property (Base \& filler metal) } \\
\text { 3) Boundary condition input } & \text { : Imaginary heat input, convection \& supporting condition }\end{array}$ \\
\hline Analysis & 1) Performing non-linear thermal-mechanical analysis \\
\hline $\begin{array}{l}\text { Post- } \\
\text { processing }\end{array}$ & $\begin{array}{l}\text { 1) Checking result of global deformation } \\
\text { 2) Rezone meshing } \\
\text { 3) Extract geometry information from results of welding analysis }\end{array}$ \\
\hline
\end{tabular}

Step II . Calculating S.F. (Shrinkage Force)

1) Derived from developed empirical formulae (Regression of Q’vs. S.F.)

\begin{tabular}{|l|l|}
\hline \multicolumn{2}{|l|}{ Step III. Thermal buckling analysis } \\
\hline $\begin{array}{l}\text { Pre- } \\
\text { processing }\end{array}$ & $\begin{array}{l}\text { 1) Modeling } \\
\text { 2) Material property input } \quad \text { : Rezoned mesh by welding analysis } \\
\text { 3) Boundary condition input } \quad \text { : S.F. input, supporting condition }\end{array}$ \\
\hline Analysis & $\begin{array}{l}\text { 1) Performing non-linear mechanical analysis } \\
\text { (Using arc length method) }\end{array}$ \\
\hline $\begin{array}{l}\text { Post- } \\
\text { processing }\end{array}$ & $\begin{array}{l}\text { 1) Checking result of global deformation } \\
\text { 2) Confirming final results }\end{array}$ \\
\hline
\end{tabular}

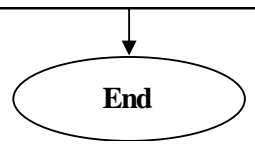

Figure 12. Procedure for the finite element analysis to predict the weld-induced distortions [42].

analysis is performed using strain-as-direct-boundary (SDB) method [43] [44]. In step II, shrinkage forces are calculated in association with the weld-induced residual stresses of welding. In step III, thermal buckling analysis is performed to determine the weld-induced distortions.

\subsection{Material Properties}

The mechanical properties of material in Table 2 are used. The yield strength of both plating and stiffeners is $309 \mathrm{MPa}$. The elastic modulus and Poisson's ratio are $203 \mathrm{GPa}$ and 0.3 , respectively. The elastic-perfectly material model without strain-hardening effect is applied.

\subsection{Thermal Loading and Boundary Conditions}

For welding analysis to obtain initial irregularity in thermal buckling analysis, contact analysis is carried out using self-weight and spring elements connected on four vertexes. The spring node constrains all six degrees of freedom to pre- 
vent rigid body motion. In order to simulate the actual welding process situation, the planar state is analyzed to the plane and the contact analysis with the structural element is carried out. The contact friction uses a stick-slip model with excellent convergence. A two-bay $(1 / 2+1+1 / 2)$ model both in the longitudinal and transverse directions is taken as the extent for the analysis as shown in Figure 13. The symmetry condition at all edges is then applied in association with structural continuity.

The thermal loads obtained from steps I and II indicated in Table 5 are applied to individual finite elements. Figure 13(a) shows the boundary conditions. The imaginary welding temperature $\left(T_{\text {top }}\right.$ and $\left.T_{b o t}\right)$ loads indicated in Table 5

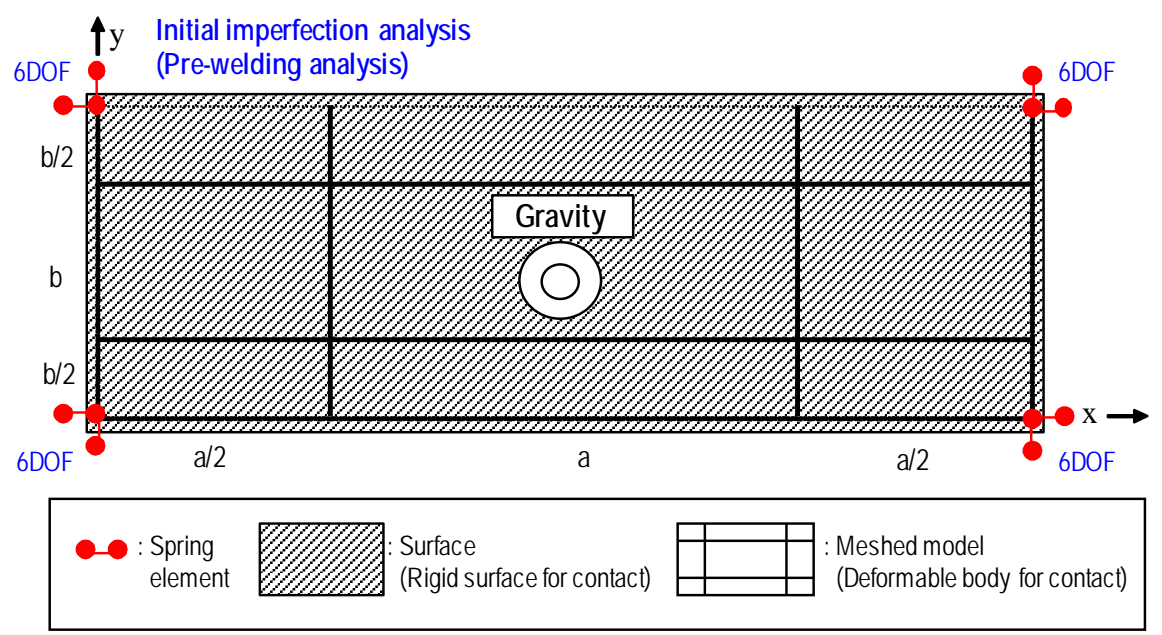

(a)

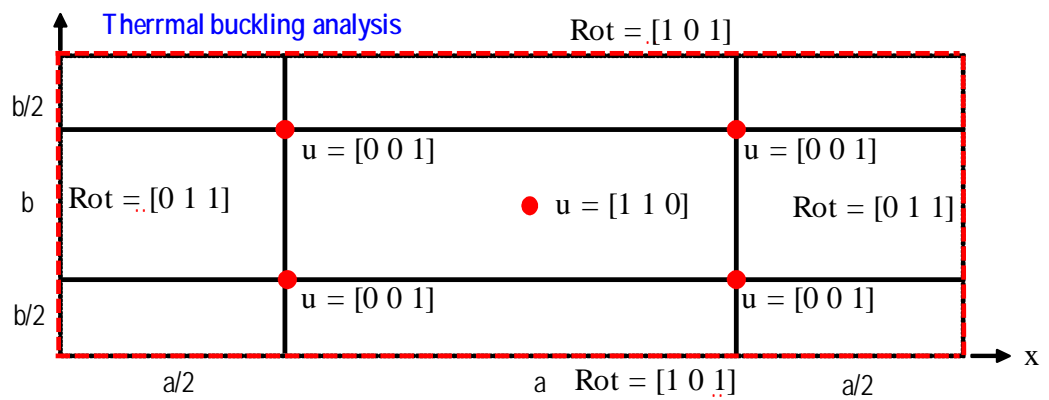

(b)

Figure 13. Extent of the analysis together with the boundary conditions [42]. (a) Initial imperfection analysis (Pre-welding analysis); (b) Thermal buckling analysis.

Table 5. Shrinkage forces depending on the plate thickness [45] [46].

\begin{tabular}{|c|c|c|c|c|}
\hline $\begin{array}{c}t_{p} \\
{[\mathrm{~mm}]}\end{array}$ & $L_{W}[\mathrm{~mm}]$ & $\begin{array}{l}\text { Shrinkage force } \\
{[\mathrm{N}]}\end{array}$ & $\begin{array}{c}\text { Imaginary } \\
\text { temperature at top, } T_{\text {top }}\left[{ }^{\circ} \mathrm{C}\right]\end{array}$ & $\begin{array}{c}\text { Imaginary } \\
\text { temperature at bottom, } T_{\text {bot }}\left[{ }^{\circ} \mathrm{C}\right]\end{array}$ \\
\hline 6 & \multirow{4}{*}{6.5} & $45,466.49$ & \multirow{4}{*}{0.174} & \multirow{4}{*}{-0.174} \\
\hline 8 & & $36,963.12$ & & \\
\hline 10 & & $31,861.09$ & & \\
\hline 12 & & $28,459.75$ & & \\
\hline
\end{tabular}


[45] [46] are applied at the top and bottom of the plates along the welding lines. After the thermal buckling analysis is completed, thermal shrinkage forces are applied to the target structure with modified boundary conditions as described in Figure 13(b).

\subsection{Computed Results and Discussion}

Figure 14 shows the computed results of the weld-induced distortions. Figure 15
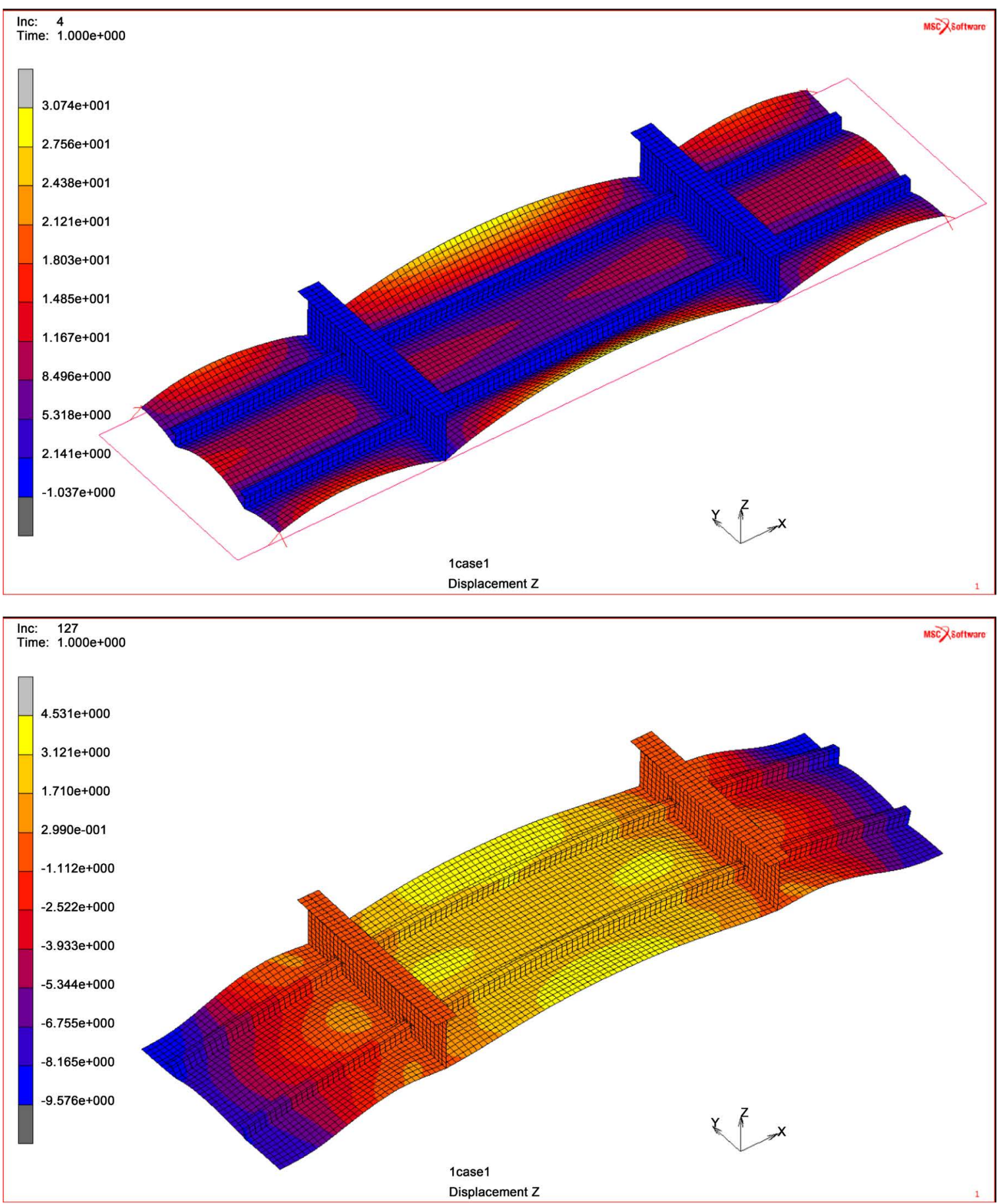

(a) 

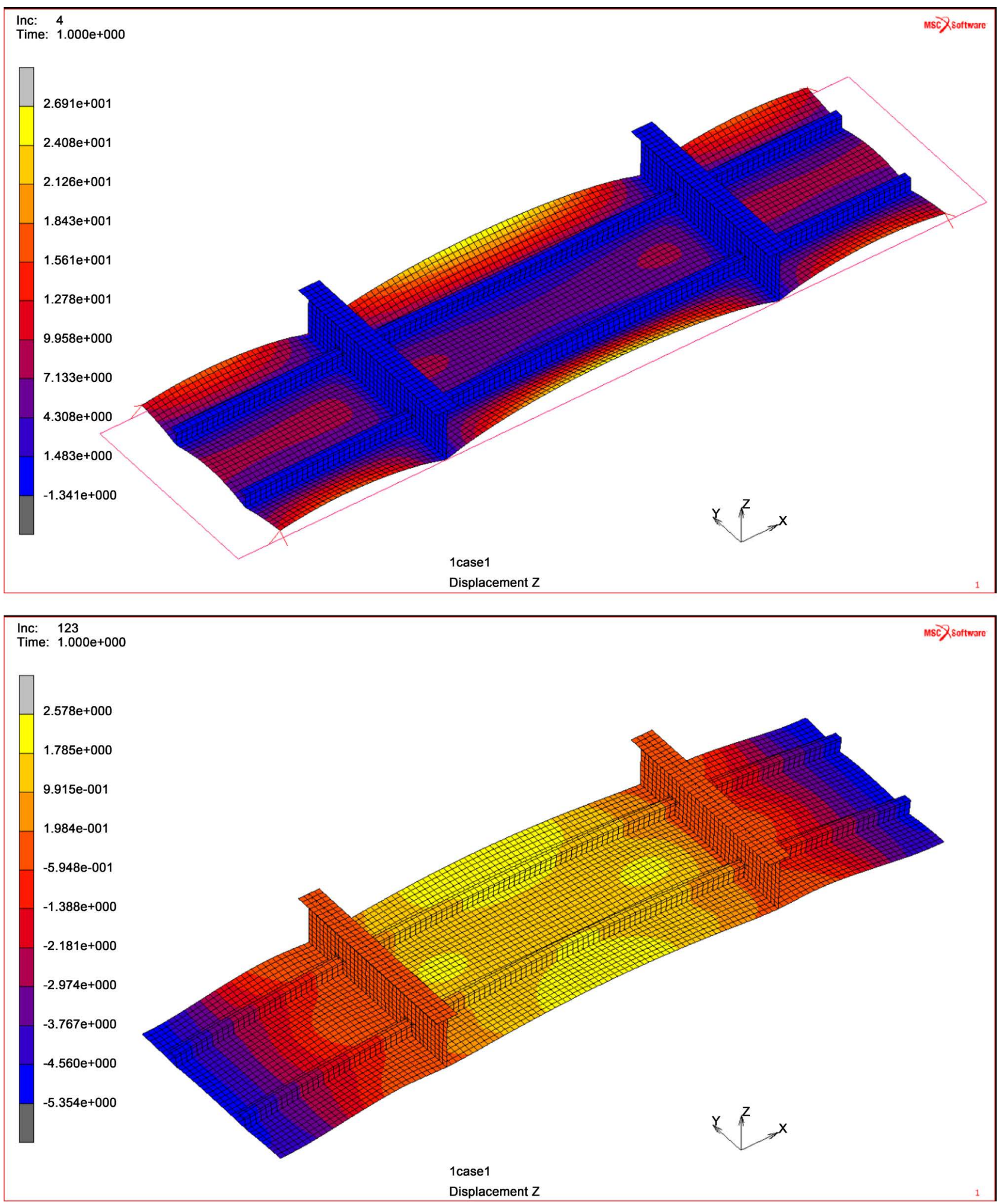

(b) 

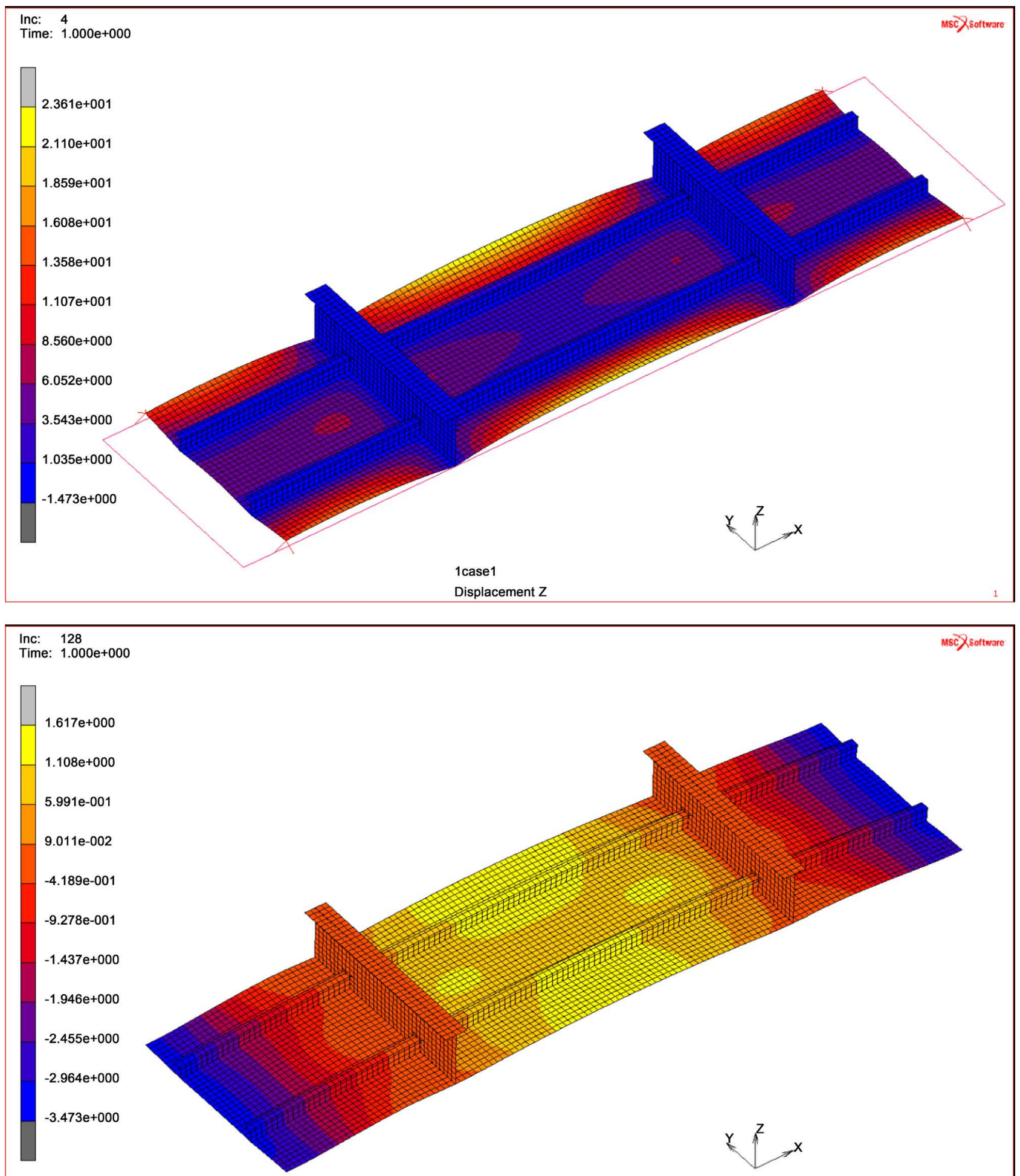

1 case 1

Displacement Z

(c) 

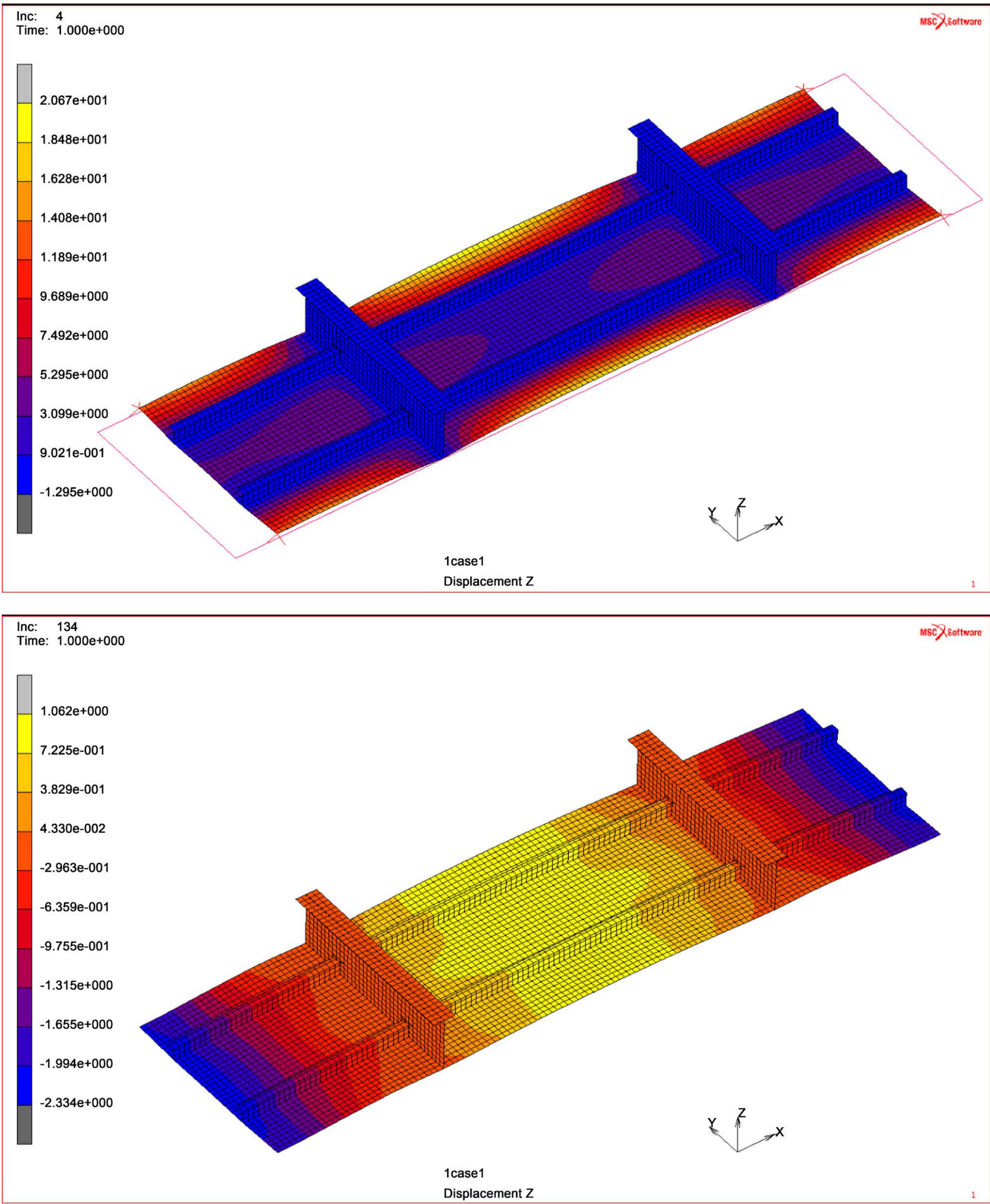

(d)

Figure 14. Computed results of the weld-induced distortions after welding. (a) Distortions of initial imperfection analysis and thermal buckling analysis for $t_{p}=6 \mathrm{~mm}$. (b) Distortions of initial imperfection analysis and thermal buckling analysis for $t_{p}=8$ $\mathrm{mm}$. (c) Distortions of initial imperfection analysis and thermal buckling analysis for $t_{p}=10 \mathrm{~mm}$. (d) Distortions of initial imperfection analysis and thermal buckling analysis for $t_{p}=12 \mathrm{~mm}$. 


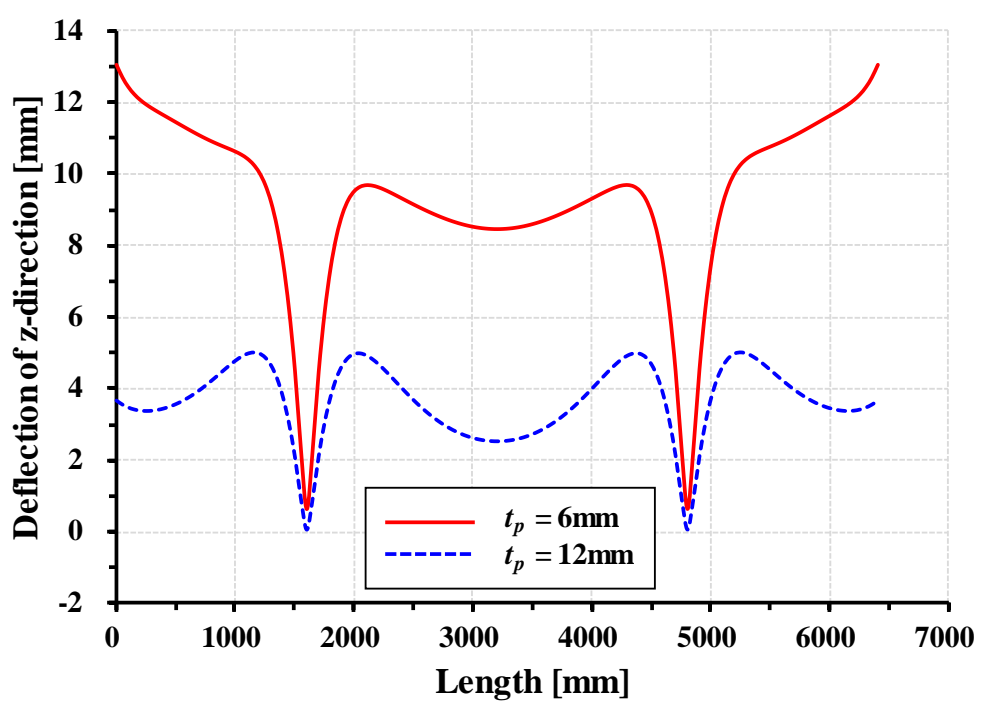

(a)

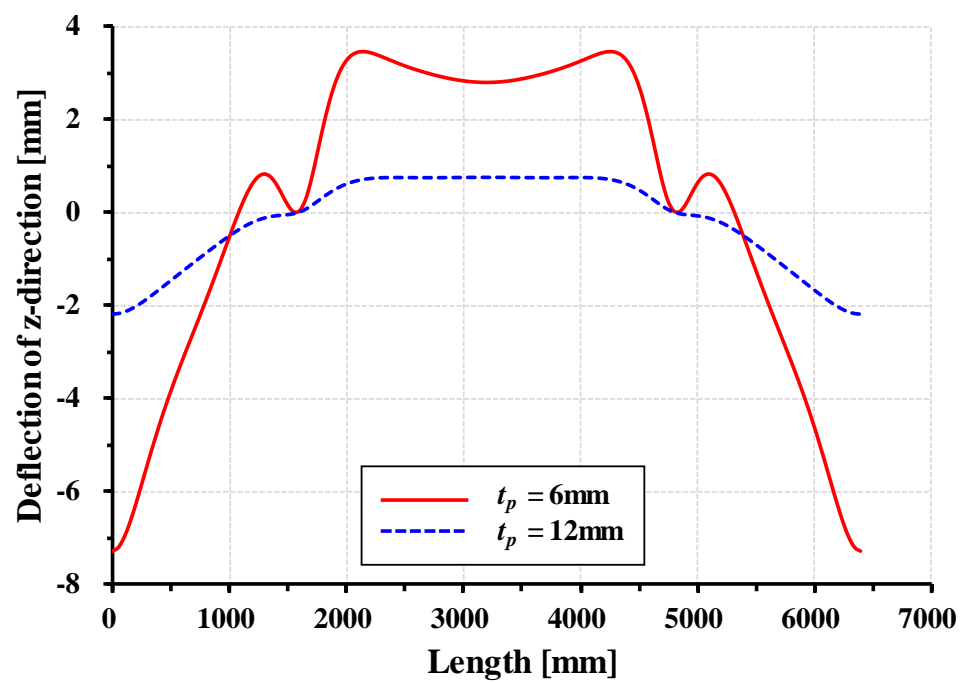

(b)

Figure 15. Computed results of the weld-induced distortions of initial imperfection (during welding) and thermal buckling analysis at plate center along the longitudinal direction. (a) Distortions of initial imperfection at the plate center in the longitudinal direction; (b) Distortions of thermal buckling analysis at plate center along the longitudinal direction.

presents the computed results of the weld-induced distortions after welding at the plate center in the longitudinal direction. According to the analysis procedure shown in Figure 12, at first welding analysis for initial imperfection was performed. The initial imperfection is assumed to be the deformation that occurs due to welding, and then thermal buckling analysis is performed by applying the shrinkage force as the boundary condition to this model. It is observed that the deflection at the welding line, i.e., on the transverse stiffeners is zero and has the maximum values at the middle of plating between stiffeners. The magnitude of the initial deflection in a thick plate is smaller than that in a thin plate. 

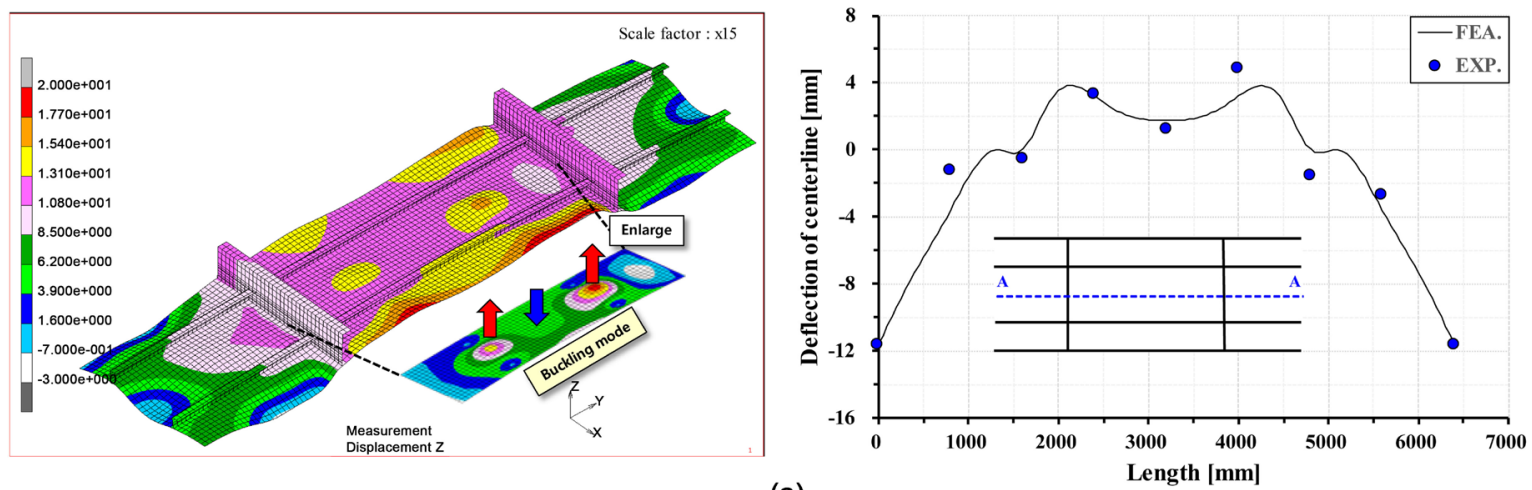

(a)
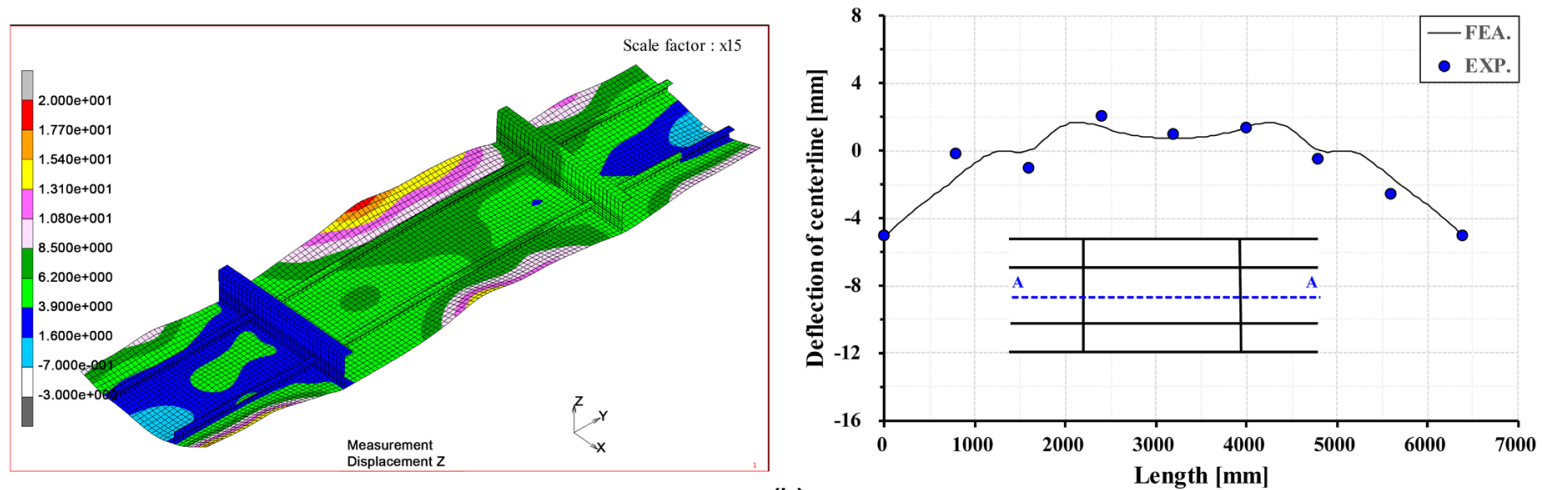

(b)
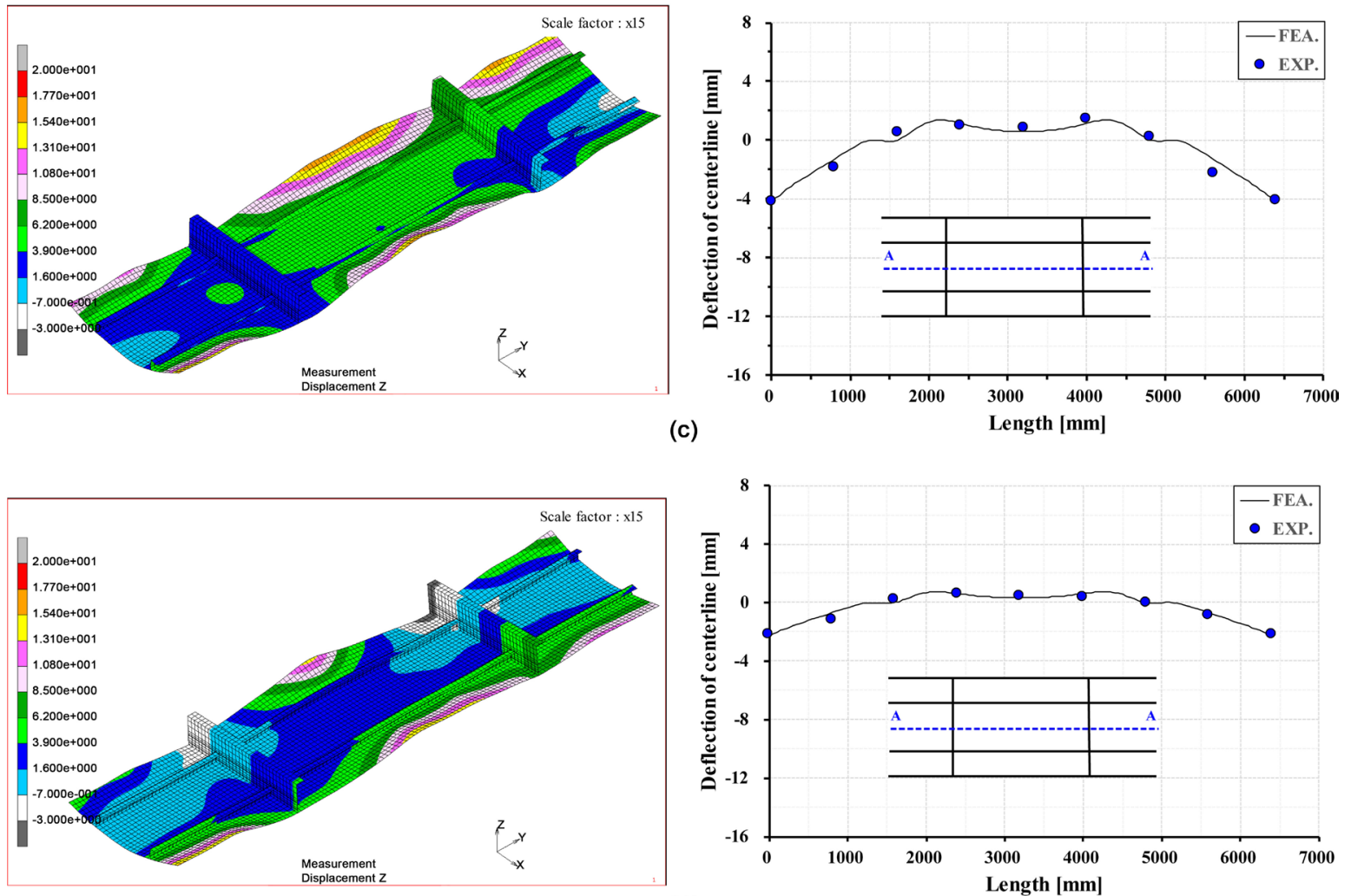

(d)

Figure 16. Comparison of weld-induced distortions between the experiment and the computations. (a) Final deflection after welding for a plate thickness of $t_{p}=6 \mathrm{~mm}$. (b) Final deflection after welding for a plate thickness of $t_{p}=8 \mathrm{~mm}$. (c) Final deflection after welding for a plate thickness of $t_{p}=10 \mathrm{~mm}$. (d) Final deflection after welding for a plate thickness of $t_{p}=12 \mathrm{~mm}$. 


\subsection{Comparison with Test Data}

Paik and Yi [36] performed the experiment to obtained test database of the welding-induced distortions in a full scale prototype structure. Figure $16 \mathrm{com}$ pares the weld-induced distortions obtained from experiment as well as the computations. It is concluded that the computations are in very good agreement with the experimental results.

\section{Conclusions}

The objectives of the present study were to develop finite element modelling techniques to predict weld-induced residual stresses and weld-induced distortions in a stiffened plate structures. The developed techniques were validated using test database obtained from direct measurements from a full scale prototype stiffened plate structures. Based on the results obtained from this study, the following conclusions are drawn.

1) In terms of predicting the weld-induced residual stresses, the modelling of heat source is important. In the present study, a double ellipsoidal shape model was applied to describe the heat source distribution during welding. It was confirmed that the numerical computations applying the proposed model are in good agreement with test data.

2) The procedure for predicting the weld-induced distortions comprises three steps, namely the weld temperature analysis, the shrinkage force computations and the thermal buckling analysis. The proposed procedure was implemented into a commercial computer code. It was confirmed that the numerical computations are in good agreement with test data.

\section{Acknowledgements}

The present study was undertaken in the Korea Ship and Offshore Research Institute at Pusan National University which has been a Lloyd's Register Foundation Research Centre of Excellence. The support of Samsung Heavy Industries is greatly acknowledged.

\section{References}

[1] Bruno, G., Yordan, G. and Soares, C.G. (2011) Effect of Weld Shape Imperfections on the Structural Hot-Spot Stress Distribution. Ships and Offshore Structures, 6, 145-159. https://doi.org/10.1080/17445302.2010.497052

[2] Teresa, M. and Craig, F. (2013) Effect of Weld-Induced Imperfections on the Ultimate Strength of an Aluminium Patrol Boat Determined by the ISFEM Rapid Assessment Method. Ships and Offshore Structures, 9, 218-235.

[3] Luís, R.M., Soares, C.G. and Nikolov, P.I. (2009) Collapse Strength of Longitudinal Plate Assemblies with Dimple Imperfections. Ships and Offshore Structures, 3, 359-370. https://doi.org/10.1080/17445300802370024

[4] Vhanmane, S. and Bhattacharya, B. (2008) Estimation of Ultimate Hull Girder Strength with Initial Imperfections. Ships and Offshore Structures, 3, 149-158. https://doi.org/10.1080/17445300802204389 
[5] Khedmati, M.R., Pedram, M. and Rigo, P. (2012) The Effects of Geometrical Imperfections on the Ultimate Strength of Aluminium Stiffened Plates Subject to Combined Uniaxial Compression and Lateral Pressure. Ships and Offshore Structures, 9 , 88-109. https://doi.org/10.1080/17445302.2012.726761

[6] Farajkhah, V., Liu, Y. and Gannon, L. (2016) Finite Element Study of 3D Simulated Welding Effect in Aluminium Plates. Ships and Offshore Structures, 12, 196-208. https://doi.org/10.1080/17445302.2015.1123865

[7] Gannon, L.G., Liu, Y., Pegg, N.G. and Smith, M.J. (2012) Effect of Three-Dimensional Welding-Induced Residual Stress and Distortion Fields on Strength and Behaviour of Flat-Bar Stiffened Panels. Ships and Offshore Structures, 8, 565-578. https://doi.org/10.1080/17445302.2012.707386

[8] Gannon, L., Liu, Y., Pegg, N. and Smith, M.J. (2015) Nonlinear Collapse Analysis of Stiffened Plates Considering Welding-Induced Residual Stress and Distortion. Ships and Offshore Structures, 11, 228-244. https://doi.org/10.1080/17445302.2014.985428

[9] Khan, I. and Zhang, S. (2011) Effects of Welding-Induced Residual Stress on Ultimate Strength of Plates and Stiffened Panels. Ships and Offshore Structures, 6, 297-309. https://doi.org/10.1080/17445301003776209

[10] Gannon, L.G., Pegg, N.G., Smith, M.J. and Liu, Y. (2013) Effect of Residual Stress Shakedown on Stiffened Plate Strength and Behaviour. Ships and Offshore Structures, 8, 638-652. https://doi.org/10.1080/17445302.2012.664429

[11] Ueda, Y. (1999) Computational Welding Mechanics (Selected from Papers Published in English). Japan Osaka: Joining and Welding Research Institute, Osaka University, Osaka.

[12] Paik, J.K. and Thayamballi, A.K. (2003) Ultimate Limit State Design of Steel-Plated Structures. Wiley, Chichester.

[13] Masubuchi, K. (1980) Analysis of Welded Structures: Residual Stresses, Distortion and Their Consequences. Pergamon Press, Oxford.

[14] Radaj, D. (1992) Heat Effects of Welding: Temperature Field, Residual Stress and Distortion. Springer Verlag Publishing, Berlin Heidelberg. https://doi.org/10.1007/978-3-642-48640-1

[15] Lindgren, L.E. (2007) Computational Welding Mechanics: Thermo Mechanical and Microstructural Simulations. Woodhead Publishing Limited, Cambridge.

[16] Goldak, J.A. and Akhlaghi, M. (2005) Computational Welding Mechanics. Springer Science \& Business Media, New York.

[17] Feng, Z. (2005) Processes and Mechanisms of Welding Residual Stress and Distortion. Woodhead Publishing Limited, Cambridge.

[18] Michaleris, P. (2011) Minimization of Welding Distortion and Buckling: Modelling and Implementation. Woodhead Publishing Limited, Cambridge. https://doi.org/10.1533/9780857092908

[19] Tsai, C.L., Park, S.C. and Chueng, W.T. (1999) Welding Distortion of a Thin-Plate Panel Structure. Welding Research Supplement, 78, 157-165.

[20] Ueda, Y. and Yamakawa, T. (1971) Analysis of Thermal Elastic-Plastic Stress and Strain during Welding by Finite Element Method. Transactions of Japan Welding Research Institute, 2, 90-100.

[21] Lindgren, L.E. and Karlsson, L. (1988) Deformations and Stresses in Welding of Shell Structures. International Journal for Numerical Methods in Engineering, 25, 635-655. https://doi.org/10.1002/nme.1620250223 
[22] Chen, B.Q., Hashemzadeh, M., Garbatov, Y. and Guedes Soares, C. (2015) Numerical and Parametric Modeling and Analysis of Weld-Induced Residual Stresses. International Journal of Mechanical and Material in Design, 11, 439-453. https://doi.org/10.1007/s10999-014-9269-7

[23] Guangming, F., Marcelo, I.L., Menglan, D. and Segen, F.E. (2016) Influence of the Welding Sequence on Residual Stress and Distortion of Fillet Welded Structures. Marine Structures, 46, 30-55. https://doi.org/10.1016/j.marstruc.2015.12.001

[24] Wang, J., Yuan, H., Ma, N. and Murakawa, H. (2016) Recent Research on Welding Distortion Prediction in Thin Plate Fabrication by Means of Elastic FE Computation. Marine Structures, 47, 42-59. https://doi.org/10.1016/j.marstruc.2016.02.004

[25] Gray, T., Camilleri, D. and McPherson, N. (2014) Control of Welding Distortion in Thin-Plate Fabrication: Design Support Exploiting Computational Simulation. Woodhead Publishing Limited, Cambridge.

[26] Deng, D., Murakawa, H. and Liang, W. (2007) Numerical Simulation of Welding Distortion in Large Structures. Computer Methods in Applied Mechanics and Engineering, 196, 4613-4627. https://doi.org/10.1016/j.cma.2007.05.023

[27] Luo, Y., Deng, D., Xie, L. and Murakawa, H. (2004) Prediction of Deformation for Large Welded Structures Based on Inherent Strain. Transactions of JWRI, 33, 65-70.

[28] Wang, R., Zhang, J.X., Serizawa, H. and Murakawa, H. (2009) Study of Welding Inherent Deformations in Thin Plates Based on Finite Analysis using Interactive Substructure Method. Materials \& Design, 30, 3474-3481.

https://doi.org/10.1016/j.matdes.2009.03.015

[29] Daniewicz, S.R., McAninch, M.D., Mc-Farland, B. and Knoll, D. (1993) Application of Distortion Control Technology during Fabrication of Large Offshore Structures. Proceedings of AWS/ ORNL International Conference on Modeling and Control of Joining Processes, Orlando, 8-10 December 1993, 239-246.

[30] Murakawa, H., Luo, Y. and Ueda, Y. (1996) Prediction of Welding Deformation and Residual Stress by Elastic FEM Based on Inherent Strain (First Report)-Mechanism of Inherent Strain Production. Journal of the Society of Naval Architects of Japan, 180, 739-751. (In Japanese) https://doi.org/10.2534/jjasnaoe1968.1996.180_739

[31] Michaleris, P. and DeBiccari, A. (1997) Prediction of Welding Distortion. Welding Journal, 76, 172-179.

[32] Yi, M.S., Kim, S.H., Kim, S.J., Seo, J.K. and Paik, J.K. (2017) Development of an Empirical Formula for Predicting Weld-Induced Initial Deflection in Steel Stiffened-Plate Structures: Numerical and Experimental Studies.

[33] Jiang, W., Luo, Y., Zhang, G. and Tu, S.-T. (2013) Experimental to Study the Effect of Multiple Weld-Repairs on Microstructure, Hardness and Residual Stress for a Stainless Steel Clad Plate. Materials \& Design, 51, 1052-1059.

https://doi.org/10.1016/j.matdes.2013.05.027

[34] Jiang, W., Xu, X.P., Gong, J.M. and Tu, S.-T. (2012) Influence of Repair Length on Residual Stress in the Repair Weld of a Clad Plate. Nuclear Engineering and Design, 246, 211-219. https://doi.org/10.1016/j.nucengdes.2012.01.021

[35] Jiang, W., Liu, Z., Gong, J.M. and Tu, S.-T. (2010) Numerical Simulation to Study the Effect of Repair Width on Residual Stresses of a Stainless Steel Clad Plate. International Journal of Pressure Vessels and Piping, 87, 457-463. https://doi.org/10.1016/j.ijpvp.2010.06.003

[36] Paik, J.K. and Yi, M.S. (2016) Experimental and Numerical Investigations of Welding-Induced Distortions and Stresses in Steel Stiffened Plate Structures. The Korea Ship and Offshore Research Institute, Pusan National University, Busan. 
[37] MSC (2013) Online User's Guide. MSC Software Corporation, Newport Beach.

[38] Rosenthal, D. (1941) Mathmatical Theory of Heat Distribution during Welding and Cutting. Welding Journal, 20, 220-234.

[39] Goldak, J., Chakravarti, A. and Bibby, M. (1984) A New Finite-Element Model for Welding Heat-Sources. Metallurgical and Materials Transactions B, 15, 299-305. https://doi.org/10.1007/BF02667333

[40] Yi, M.S. (2006) The Effect of Geometry Non-Linearity in Welding Deformation. Ms.D. Thesis, Pusan National University, Busan. (In Korean)

[41] Yi, M.S., Hyun, C.M., Cho, S.H. and Jang, T.W. (2009) A Study of Correction Effect in T-Bar According to Cooling Method. Proceeding of the 2009 Spring Annual Meeting of Korea Welding Society, Changwon, 21-22 April 2009, 60. (In Korean)

[42] Yi, M.S., Hyun, C.M. and Yoo, J.S. (2016) Development of New Thermal Buckling Analysis Technique Caused by Welding. International Welding/Joining Conference, Gyeongju, 11-14 April 2017, 21.

[43] Ha, Y.S., Cho, S.H. and Jang, T.W. (2008) Development of Welding Distortion Analysis Method using Residual Strain as Boundary Condition. Material Science Forum, 580-582, 649-654.

https://doi.org/10.4028/www.scientific.net/MSF.580-582.649

[44] Ha, Y. (2011) A Study on Weldment Boundary Condition for Elasto-Plastic Thermal Distortion Analysis of Large Welded Structures. Journal of Welding and Joining, 29, 410-415. https://doi.org/10.5781/KWJS.2011.29.4.410

[45] Shin, S.B., Kim, K.K. and You, J.G. (2006) A Study on Control of Buckling Distortion at the Thin Panel during Welding. International Offshore and Polar Engineering Conference, San Francisco, CA, 28 May-2 June 2006, 236-242.

[46] Lee, D.J. and Shin, S.B. (2003) A Study on the Prediction of Shrinkage during the Manufacturing of a Deckhouse of RIG. International Offshore and Polar Engineering Conference, Honolulu, 25-30 May 2003, 166-171. 